\title{
Supramolecular architectures and structural diversity in a series of lead (II) Chelates involving 5-Chloro/Bromo thiophene-2-carboxylate and N, $\mathrm{N}^{\prime}$-donor ligands
}

Samson Jegan Jennifer and Packianathan Thomas Muthiah*

\begin{abstract}
Background: Lead is a heavy toxic metal element in biological systems and is one of the major pollutants as a result of its widespread use in industries. In spite of its negative roles the coordination chemistry of $\mathrm{Pb}(\mathrm{II})$ complexes is a matter of interest. The N,N'-bidentate aromatic bases such as BPY,4-BPY and PHEN (BPY = 2,2'bipyridine, 4-BPY = 4,4'-dimethyl-2,2'-bipyridine, $\mathrm{PHEN}=1,10$-Phenanthroline) are widely used to build supramolecular architectures because of their excellent coordinating ability and large conjugated system that can easily form $\pi-\pi$ interactions among their aromatic moieties. A series of novel $\mathrm{Pb}(\mathrm{II})$ complexes in concert with 5-CTPC, 5-BTPC (5-CTPC = 5-chlorothiophen-2-carboxylate, 5-BTPC = 5-bromothiophen-2-carboxylate) and corresponding bidentate chelating N.N' ligands have been synthesized and characterized.

Results: Five new Pb (II) complexes $\left[\mathrm{Pb}(\mathrm{BPY})(5-\mathrm{CTPC})_{2}\right]$ (1), [Pb(4-BPY)(5-CTPC) $)_{2}(2),\left[\mathrm{Pb}_{2}(\mathrm{PHEN})_{2}(5-\mathrm{CTPC})_{4}\right]$ (3), $\left[\mathrm{Pb}(4-\mathrm{BPY})(5-\mathrm{BTPC})_{2}\right](4)$ and $\left[\mathrm{Pb}_{2}(\mathrm{PHEN})_{2}(5-\mathrm{BTPC})_{2}(\mathrm{ACE})_{2}\right]$ (5) have been synthesized. Even though in all these complexes the molar ratio of $\mathrm{Pb}$, carboxylate, $\mathrm{N}, \mathrm{N}$-chelating ligand are the same $(1: 2: 1)$, there is a significant structural diversity. These complexes have been characterised and investigated by elemental analysis, IR, ${ }^{1} \mathrm{H}-\mathrm{NMR},{ }^{13} \mathrm{C}-\mathrm{NMR}, \mathrm{TGA}$, and photoluminescence studies. Single crystal $\mathrm{X}$-ray diffraction studies reveal that complexes $(1,2)$ and $(4)$ are mononuclear while $(3$ and 5$)$ are dinuclear in nature which may result from the chelating nature of the ligands, various coordination modes of the carboxylates, and the coordination geometry of the $\mathrm{Pb}(\mathrm{II})$ ions.

Conclusions: The observation of structures 2,4 and 3,5 show the structural changes made just chloro/bromo substituent of the thiophene ring. A detailed packing analysis has been undertaken to delineate the role of valuable non covalent interactions like $\mathrm{X} \ldots \pi, \mathrm{H} \ldots \mathrm{X},(\mathrm{X}=\mathrm{Cl} / \mathrm{Br})$. A quadruple hydrogen bond linking the monomeric units and generating a supramolecular architecture is observed in (1). The metal bite unit comprised of $\mathrm{PbN}_{2} \mathrm{C}_{2}$ (i.e. $\mathrm{Pb}-\mathrm{N}-\mathrm{C}-\mathrm{C}-\mathrm{N}-\mathrm{Pb}$ ) is the repeating unit in all the five complexes and they have almost same geometrical parameters. This metal bite has been identified as the self assembly unit in complexes.
\end{abstract}

Keywords: Metal bite, Lone pair, Phenanthroline, 5-chlorothiophen-2-carboxylic acid, Pb(II), Halogen bonding

* Correspondence: tommtrichy@yahoo.co.in

School of Chemistry, Tiruchirappalli, Tamil Nadu 620024, India 


\section{Background}

The molecular self assembly with discrete supramolecular units directed by metal ligand coordination and weak interactions are of considerable interest [1-6]. The interplay of coordination motifs and supramolecular synthons are of current interest to generate novel materials (metal organic frameworks (MOF's), coordination polymers, inorganic hybrid materials, etc.). When a sensible choice of the central metal ion and a ligand whose favourite coordination modes are known one can design an anticipated variety of supramolecular motifs [6-10].

Lead is a heavy toxic metal element in biological systems and is one of the major pollutants as a result of its widespread use in industries. In spite of its negative roles the coordination chemistry of $\mathrm{Pb}(\mathrm{II})$ complexes is a matter of interest, which display interesting structural features as a consequence of the large radius, adoption of different coordination numbers from 2 to 10 and especially based on the extent to which the lone pair is stereo chemically active [11-15]. A common strategy followed in designing of the $\mathrm{Pb}(\mathrm{II})$ complexes is the presence of carboxylate and bipyridne systems in the coordination sphere [16-33]. Lead(II) carboxylate systems containing mono, di and polycarboxylate have been extensively used in the construction of metal organic networks [23-33]. The N,N'bidentate aromatic bases such as BPY,4-BPY and PHEN are widely used to build supramolecular architectures because of their excellent coordinating ability and large conjugated system that can easily form $\pi-\pi$ interactions among their aromatic moieties, which are either intra or intermolecular [16-22]. The thiophene carboxylates possess various coordination modes such as monodentate, bidentate chelating, bidentate bridging when coordinated to the metal ion (Scheme 1). The rigid heterocyclic five member thiophene ring possesses distinct physical and chemical properties [34,35]. Also in this heterocyclic thiophene ring the relatively bigger size of the sulphur atom makes the possibility for delocalisation of its lone pair of electrons, which results in good charge transfer ability of the ligand [35].

Our strategy is to investigate the chelating behaviour of these ligands towards lead (II) along 5-CTPC and 5BTPC. In all the five complexes BPY, 4-BPY and PHEN act as a nitrogen donor ligand forming $3 \mathrm{D}$ supramolecular architectures in the solid state. Although there are some reports of diverse coordination polymers involving multicarboxylate ligands containing $\mathrm{S}$ atom and bidentate chelating ligands like PHEN, 2-BPY as well as bridging ligand such as 4-4'-bipyridine as coligands [36-41], there are only a few reports involving the halo substituted thiophene carboxylate ligand for the construction of organic-inorganic hybrids [42]. 5-CTPC not only shows versatile coordination modes but also exhibits non covalent interactions like $\mathrm{Cl}$... $\pi$ and $\mathrm{C}-\mathrm{H}$...Cl [42-45]. In our present investigation of five $\mathrm{Pb}$ (II) complexes, we have observed the different coordination number, and different coordination modes of the carboxylate ligand which gives the idea of constructing different supramolecular architectures. The coordination modes of the carboxylate group, observed in these

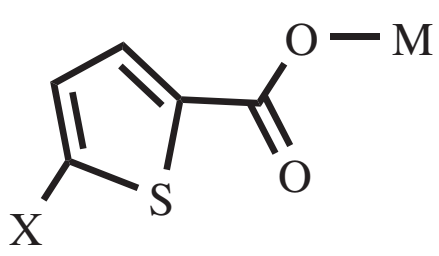

a

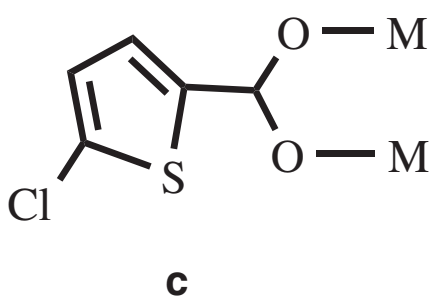

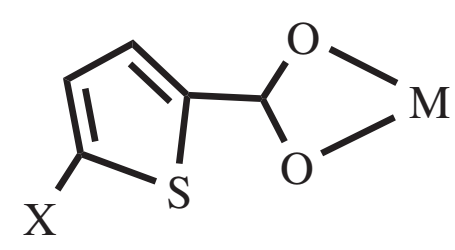

b

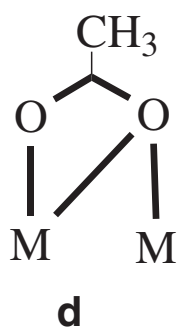

Scheme 1 Coordination modes of 5-CTPC, 5-BTPC and acetate. (a) X=Cl in 4 (b) $\mathrm{X}=\mathrm{Cl}, \mathrm{Br}$ in 2 and 4 respectively, where $\mathrm{M}=\mathrm{Pb}$. 
Table 1 Comparison of coordination modes of various carboxylates

\begin{tabular}{llll}
\hline Complex & Caboxylate & Type of coordination & Geometry \\
\hline 1 & 5-CTPC & Bidentate chelating & $\begin{array}{l}\text { Pentagonal } \\
\text { pyramidal }\end{array}$ \\
2 & 5-CTPC & Bidentate chelating & $\begin{array}{l}\text { Pentagonal } \\
\text { pyramidal } \\
\text { Capped square } \\
\text { pyramidal }\end{array}$ \\
4 & 5-CTPC & $\begin{array}{l}\text { Bidentate chelating, } \\
\text { Bidentate bridging }\end{array}$ & $\begin{array}{l}\text { Distorted square } \\
\text { pyramidal }\end{array}$ \\
5 & 5-BTPC & $\begin{array}{l}\text { Bidentate chelating, } \\
\text { Monodentate }\end{array}$ & $\begin{array}{l}\text { Pentagonal } \\
\text { bipyramidal }\end{array}$ \\
& 5-BTPC & $\begin{array}{l}\text { Bidentate chelating } \\
\text { Bidentate chelating } \\
\text { bridging }\end{array}$ & \\
\hline
\end{tabular}

$\mathrm{Pb}(\mathrm{II})$ complexes are shown in scheme.1. In addition a previously reported complex $\left[\mathrm{Pb}(\mathrm{TPC})_{2}(\mathrm{PHEN})\right](\mathrm{TPC}=$ Thiophene 2- carboxylic acid) has been compared with structures $(3,5)[46]$.

\section{Results and discussion \\ Geometry around lead}

The lone pair of electrons has a great influence on the structure of the complex $[11,47,48]$. In the coordination chemistry of the $\mathrm{Pb}(\mathrm{II})$ ion, the terms holo and hemi directed are used to describe the geometries around the central $\mathrm{Pb}$ atom. $\mathrm{Pb}(\mathrm{II})$ complexes where the bonds to ligand atoms are placed throughout the surface of the encompassing globe are said to be holo directed, while hemidirected refers to those cases in which the bonds to ligand atoms are directed throughout only part of an encompassing globe [49]. The coordination numbers of lead in complexes 1 and 2 are six, and they exhibit a pentagonal pyramidal geometry. While the coordination numbers of 4 and 5 are five and seven respectively, and they show distorted square pyramidal and distorted pentagonal bipyramidal geometry respectively. Comparison of coordination modes of the carboxylates are listed in (Table 1). The structure 3 shows an unusual capped square pyramidal geometry. In complex 1, the axial position of the pentagonal pyramid is occupied by the N1 of the BPY by which it differs from 2 where this position is occupied by $\mathrm{O} 4$ of the 5 -CTPC (Figure 1). In 4 the axial position is occupied by $\mathrm{O} 3$ of the 5-BTPC. The coordination geometry of complexes $1-3,4$ as well as the $\mathrm{Pb}-\mathrm{O}$ and the $\mathrm{Pb}-\mathrm{N}$ bond directions show a gap around the $\mathrm{Pb}$ (II) ion, occupied possibly by a stereoactive lone pair of electrons on lead(II). The coordination around the lead atoms is hemidirected with a significant gap trans to chelating BPY, 4-BPY and PHEN ligands (Figure 1). In 5 PHEN is a space demanding ligand upon coordination with the $\mathrm{Pb}$ (II) ion it forms a seven coordinated holodirected distorted pentagonal bipyramidal complex instead a hemidirected one with less coordination number. The hemidirected geometry is the most preferred for intermediate coordination numbers between 6-8 [50]. There is a $\pi-\pi$ stacking interaction, the parallel aromatic rings belonging to adjacent chains in complexes 1,2 and 3 that may help to increase the 'gap' in the coordination geometry around the $\mathrm{Pb}(\mathrm{II})$ ion.

\section{Crystal structure description of $\left[\mathrm{Pb}(\mathrm{BPY})(5-\mathrm{CTPC})_{2}\right](1)$}

Single-crystal X-ray diffraction analysis reveals that complex 1 consists of a monomeric $\mathrm{Pb}(\mathrm{II})$ ion, a BPY and two bidentate (5-CTPC) molecules as shown in (Figure 2). Each $\mathrm{Pb}(\mathrm{II})$ ion is a hexa coordinated environment with

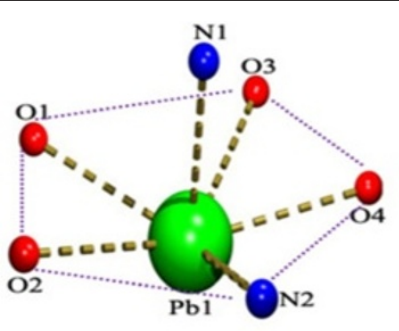

a

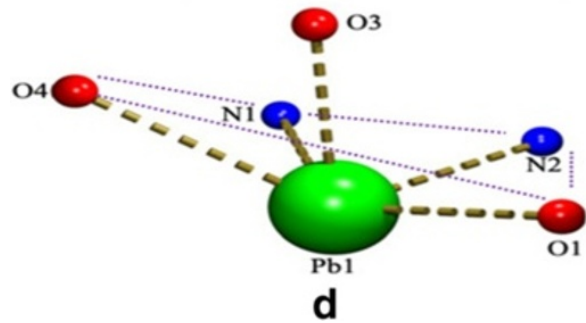

b
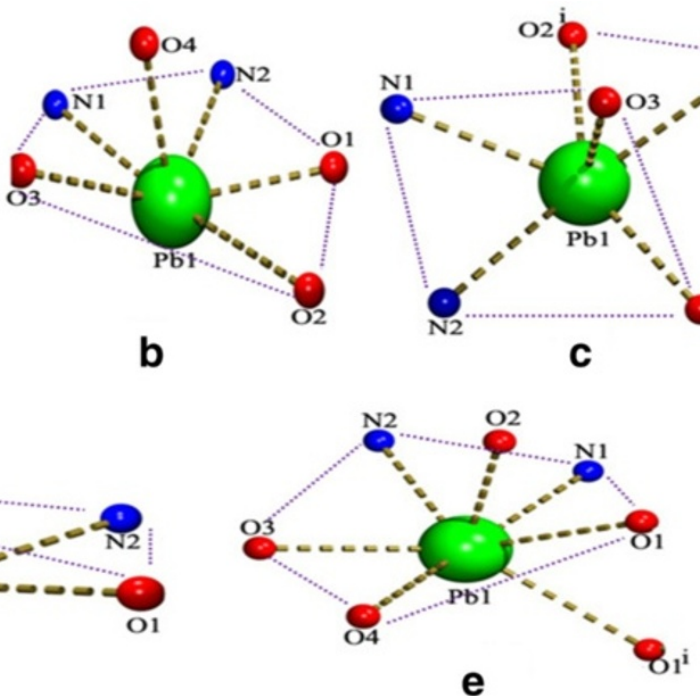

Figure 1 Comparison of coordination environment around the $\mathrm{Pb}$ (II) ions showing the geometries. (a) Complex 1; (b) Complex 2; (c) Complex 3; (d) Complex 4 and (e) Complex 5. 


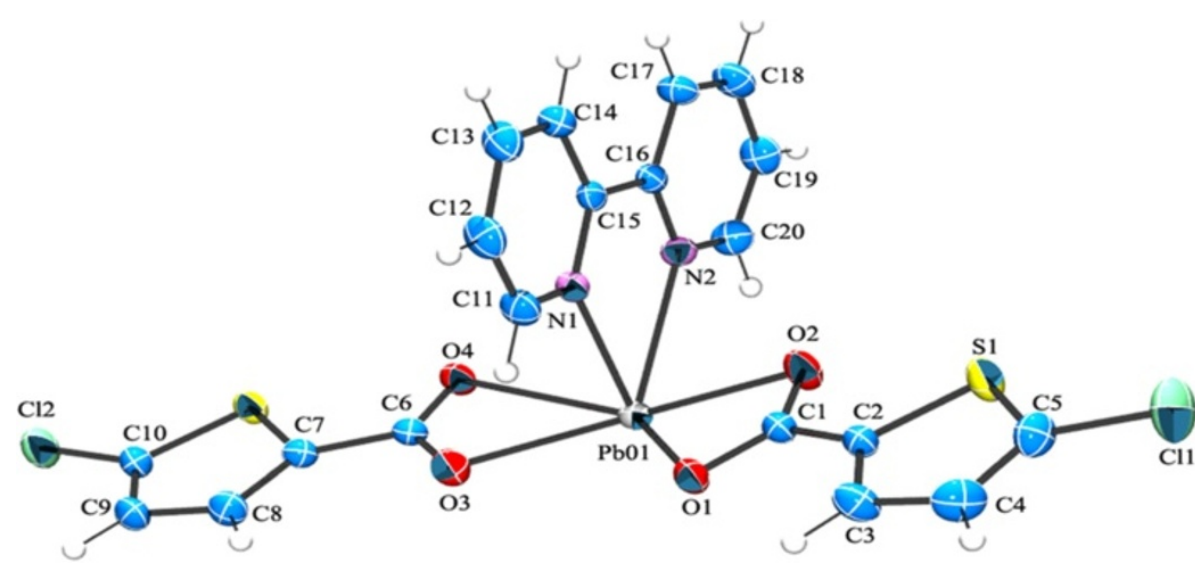

Figure 2 ORTEP of complex 1 showing the atom-numbering scheme with displacement ellipsoids drawn at $50 \%$ probability level for all non hydrogen atoms and $\mathrm{H}$ atoms are shown as small spheres of arbitrary radii.

two nitrogen from a chelating BPY molecule with a $\mathrm{Pb}-\mathrm{N}$ bond distances (2.481(2) $\AA$ and 2.595(2) $\mathrm{A}$ ) and four oxygen atoms from two bidentate 5-CTPC molecules with the $\mathrm{Pb}-\mathrm{O}$ bond lengths ranging from $2.532(2) \AA$ to 2.624(2) $\AA$.

The monomeric units are strongly linked to each other by a quadruple hydrogen bonding motif consisting of four C-H. . .O hydrogen bonding interactions (inbetween the hydrogens of the thiophene ring and oxygen from the bidentate-chelating coordinated carboxyl) (Table 2, Figure 3). The quadruple hydrogen bonds fused by three rings, which can be represented by the graph-set notation $\mathrm{R}_{2}^{2}(7), \mathrm{R}_{2}^{2}(10), \mathrm{R}_{2}^{2}(7)$ (Figure 4) [51]. Thus it forms a dimer made of quadruple hydrogen bonds. Surprisingly inbetween the adjoining units there is a weak coordination bond $(\mathrm{PbO} 1-\mathrm{O} 1=3.060 \AA$ ). A similar structural unit with same $\mathrm{Pb}-\mathrm{O}$ weak coordination bond has been reported earlier [46].

Thus these dimers are further interdigited to each other by the $\pi-\pi$ stacking interactions between the bipyridine rings leading to one dimensional infinite chains $\mathrm{Cg} 1 \rightarrow \mathrm{Cg} 2^{\mathrm{ii}}$ and $\mathrm{Cg} 2 \rightarrow \mathrm{Cg} 1^{\text {ii }}$ [Symmetry code ii: $2-\mathrm{X},-\mathrm{Y}, 1-\mathrm{Z}](\mathrm{Cg} 1=\mathrm{N} 1, \mathrm{C} 11-\mathrm{C} 15$ and $\mathrm{Cg} 2=\mathrm{N} 2, \mathrm{C} 16-\mathrm{C} 20)$ (Figure 3). Further the chains are connected to each

Table 2 Hydrogen bond metrics for complexes 1-5

\begin{tabular}{|c|c|c|c|c|}
\hline D-H....A & H...A (Á) & D...A (Á) & LD -H...A & Symmetry operation \\
\hline \multicolumn{5}{|c|}{ [Pb(BPY)(5-CTPC)2] (1) } \\
\hline $\mathrm{C} 8-\mathrm{H} 8 \ldots \mathrm{O} 3$ & 2.5300 & $3.334(4)$ & 145.00 & $3-x, 1-y, 2-z$ \\
\hline $\mathrm{C} 9-\mathrm{H} 9 \ldots \mathrm{O} 1$ & 2.4200 & $3.318(4)$ & 163.00 & $3-x, 1-y, 2-z$ \\
\hline $\mathrm{C} 14-\mathrm{H} 14 \ldots \mathrm{O} 4$ & 2.4700 & $3.364(4)$ & 162.00 & $2-x,-y, 1-z$ \\
\hline $\mathrm{C} 17-\mathrm{H} 17 \ldots \mathrm{O} 4$ & 2.4700 & $3.351(4)$ & 158.00 & $2-x,-y, 1-z$ \\
\hline $\mathrm{C} 18-\mathrm{H} 18 \ldots \mathrm{O} 2$ & 2.5300 & $3.273(4)$ & 137.00 & $1-x,-y, 1-z$ \\
\hline \multicolumn{5}{|c|}{$[\mathrm{Pb}(4-\mathrm{BPY})(5-\mathrm{CTPC}) 2](2)$} \\
\hline $\mathrm{C} 9-\mathrm{H} 9 \ldots \mathrm{O} 2$ & 2.56 & $3.437(4)$ & 157 & $2-x, 1-y,-z$ \\
\hline \multicolumn{5}{|c|}{ [Pb2(PHEN)2(5-CTPC)4] (3) } \\
\hline $\mathrm{C} 4-\mathrm{H} 4 \ldots \mathrm{Cl} 1$ & 2.8100 & $3.617(4)$ & 146.00 & $-2-x,-y,-z$ \\
\hline $\mathrm{C} 11-\mathrm{H} 11 \ldots \mathrm{O} 2$ & 2.5000 & $3.143(5)$ & 127.00 & $-x, 1-y, 1-z$ \\
\hline \multicolumn{5}{|c|}{$[\mathrm{Pb}(4-\mathrm{BPY})(5-\mathrm{BTPC}) 2](4)$} \\
\hline $\mathrm{C} 22-\mathrm{H} 22 \mathrm{~A} \ldots \mathrm{Br} 1$ & 2.8700 & $3.791(5)$ & 162.00 & $2-x,-y, 2-z$ \\
\hline $\mathrm{C} 9-\mathrm{H} 9 \ldots \mathrm{O} 2$ & 2.5600 & $3.424(6)$ & 155.00 & $2-x, 1-y, 1-z$ \\
\hline \multicolumn{5}{|c|}{ [Pb2(PHEN)2(5-BTPC)2(ACE)2] (5) } \\
\hline $\mathrm{C} 8-\mathrm{H} 8 \ldots \mathrm{O} 1$ & 2.6000 & $3.325(5)$ & 135.00 & $2-x, 1-y, 1-z$ \\
\hline $\mathrm{C} 8-\mathrm{H} 8 \ldots \mathrm{O} 4$ & 2.4600 & $3.149(8)$ & 130.00 & $2-x, 1-y, 1-z$ \\
\hline $\mathrm{C} 15-\mathrm{H} 15 \ldots \mathrm{O} 2$ & 2.5200 & $3.109(7)$ & 121.00 & $2-x, 1-y, 2-z$ \\
\hline
\end{tabular}




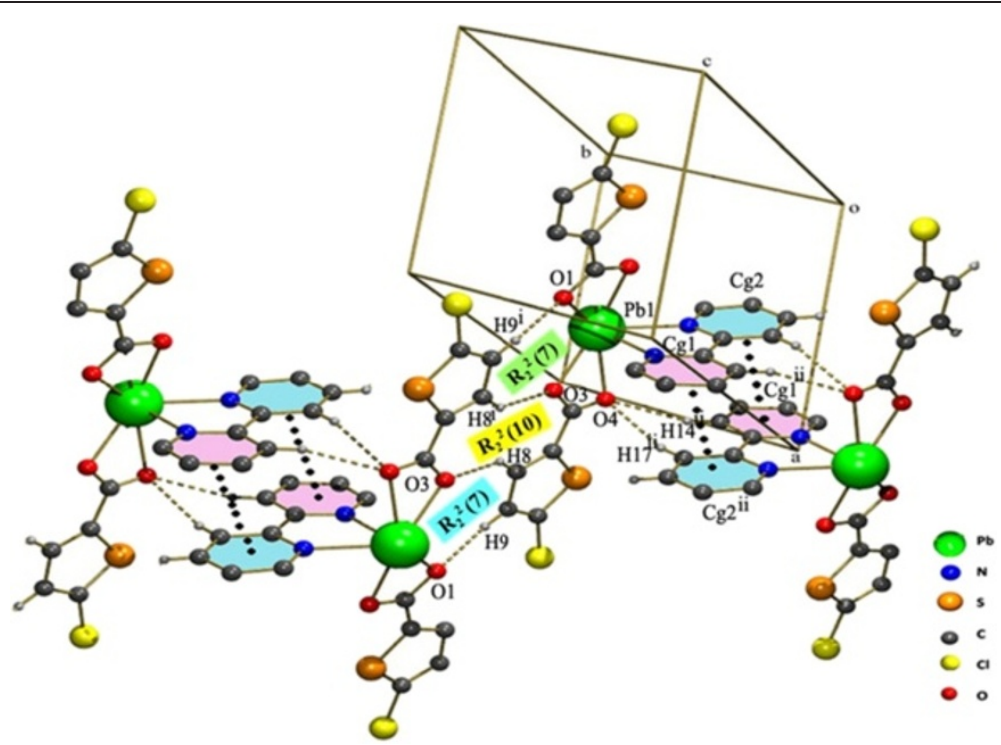

Figure 3 View of 1 showing the 1D chain made up of C-H...O interactions and the $\pi-\pi$ stacking inetractions. The hydrogen atoms which are not involved in hydrogen bonding are omitted for clarity.

other by the $\mathrm{Cl} \cdots \pi$ interaction found inbetween the $\mathrm{Cl} 1$ of the five member thiophene ring involving (S1,C2-C5) and the six membered N-hetero ring of the BIPY involving (N1,C11-C15) (Figure 4).

\section{Crystal structure description of $\left[\mathrm{Pb}(4-\mathrm{BPY})(5-\mathrm{CTPC})_{2}\right](2)$}

The core structure of $\mathbf{2}$ is very similar to that of 1 and it consists of one $\mathrm{Pb}(\mathrm{II})$ ion, a 4-BPY and two bidentate
(5-CTPC) molecules as shown in (Figure 5). Each Pb(II) ion has a hexa coordinated environment with two nitrogen from a chelating 4-BPY molecule with a $\mathrm{Pb}-\mathrm{N}$ bond distances (2.593(2) $\AA$ and 2.626(2) $\AA$ ) and four oxygen atoms from two bidentate 5-CTPC molecules with the $\mathrm{Pb}-\mathrm{O}$ bond lengths ranging from $(2.3469(19) \AA$ to 3.019(2) $\AA$ ). Although the coordination geometry of lead (II) ion is same for both complexes 1 and 2, they differ in the atoms

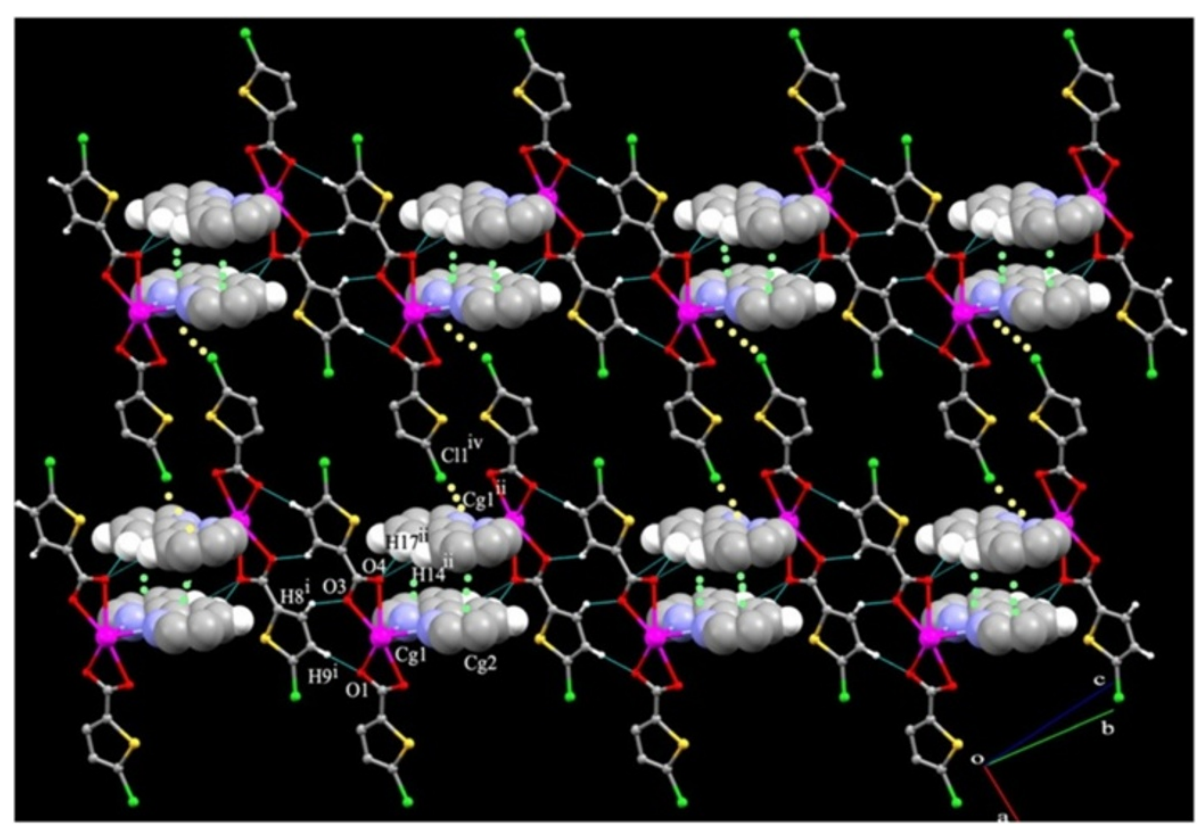

Figure 4 Crystal packing in 1 showing the $\mathrm{Cl}$...Cg interactions. 


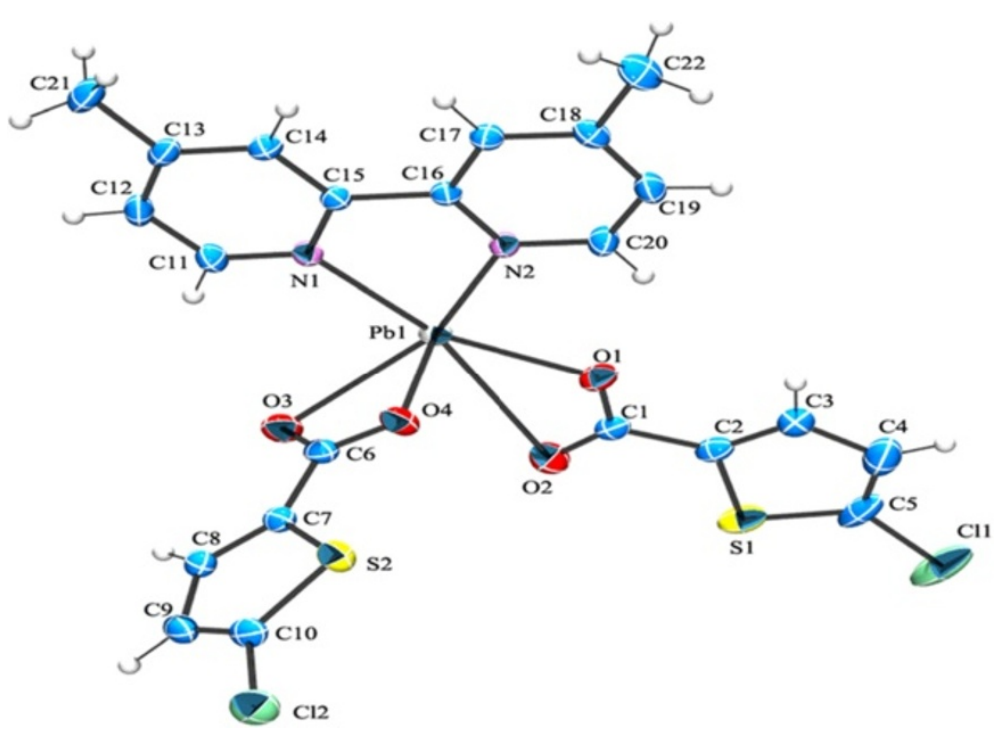

Figure 5 ORTEP of complex 2 showing the atom-numbering scheme. Displacement ellipsoids are drawn at the 50\% probability level for all non hydrogen atoms and $\mathrm{H}$ atoms are shown as small spheres of arbitrary radii.

coordinated at the apical site of the pentagonal pyramid. In 1 it is occupied by the $\mathrm{N} 1$ (Pb-N1 2.481(2) $\AA$ ) of the bidentate BPY ligand while in 2 it is occupied by the $\mathrm{O} 4$ (Pb-O4 2.3469(19) $\AA$ ) of the 5-CTPC.

The monomeric units are linked by $\mathrm{C}-\mathrm{H}$. . .O interaction between $\mathrm{C} 9-\mathrm{H} 9 \ldots \mathrm{O}^{\mathrm{i}}$ [Symmetry code i: $2-\mathrm{x}, 1-\mathrm{y},-\mathrm{z}$ ] and $\pi-\pi$ stacking interactions inbetween two five member rings $\mathrm{Cg} 2 \rightarrow \mathrm{Cg}_{2}{ }^{\mathrm{ii}}$ where $\mathrm{Cg} 2=\mathrm{S} 2, \mathrm{C} 7-\mathrm{C} 10$ [symmetry code ii: 2-X,1-Y,-Z] (Figure 6). Thus these interactions forms I shaped dimers (Figure 6). This I shaped dimer is nailed to the two other I shaped dimer on its adjacent sides by two sets of $\pi-\pi$ stacking interactions $(\mathrm{Cg} 1 \rightarrow$ $\mathrm{Cg} 3^{\text {iv }}$ on one side and $\mathrm{Cg} 3 \rightarrow \mathrm{Cg} 4^{\mathrm{iii}}, \mathrm{Cg} 4 \rightarrow \mathrm{Cg} 3^{\text {iii }}$ on the other side). Another pi-pi stacking is found between the two six member rings of the two adjacent 4-BPY ligands.

\section{Crystal structure of description of $\left[\mathrm{Pb}_{2}(\mathrm{PHEN})_{2}(5-\mathrm{CTPC})_{4}\right]$}

(3)

The complex 3 contains a dinuclear lead unit with two carboxylate groups bridging the lead atoms ( $\mathrm{Pb}-\mathrm{O}-\mathrm{C}-\mathrm{O}-$

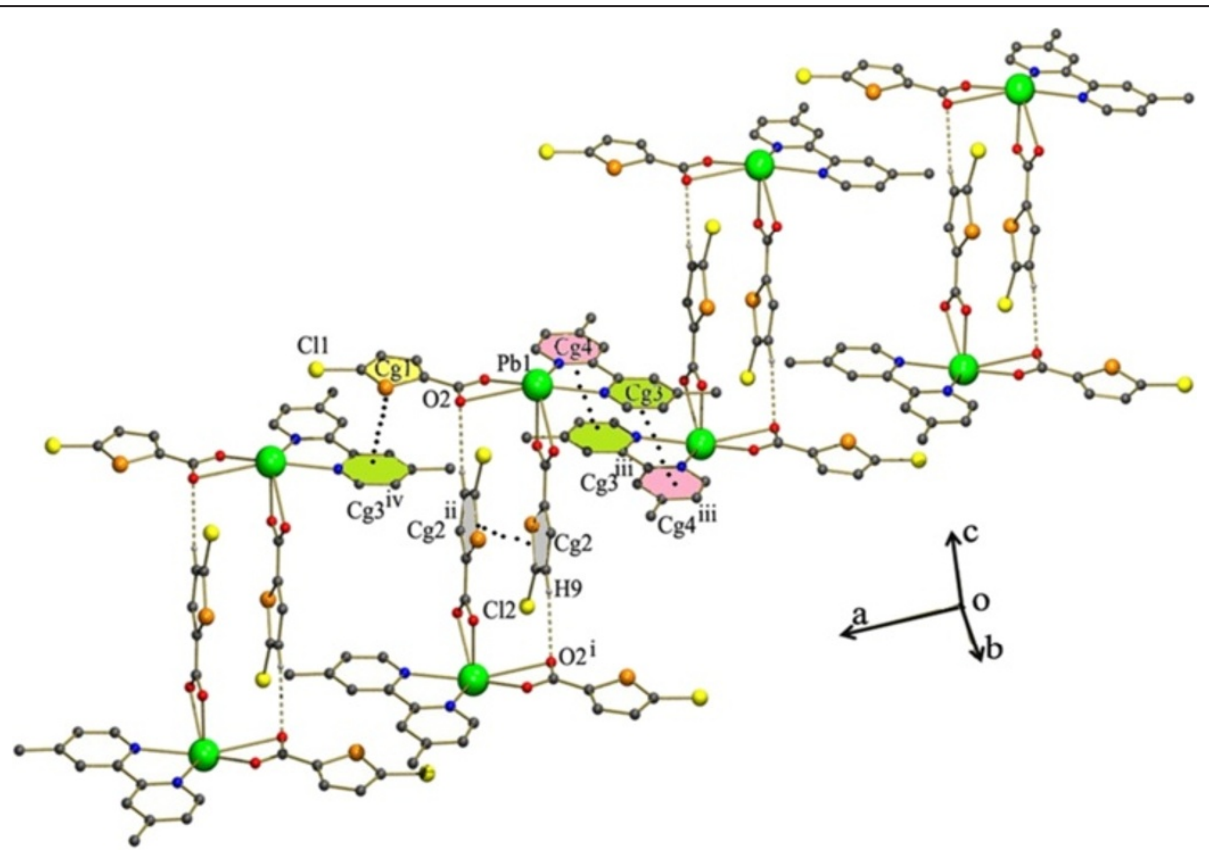

Figure 6 Perspective view of 2 showing the I shaped dimer formed by C-H...O and $\pi-\pi$ stacking interactions. 


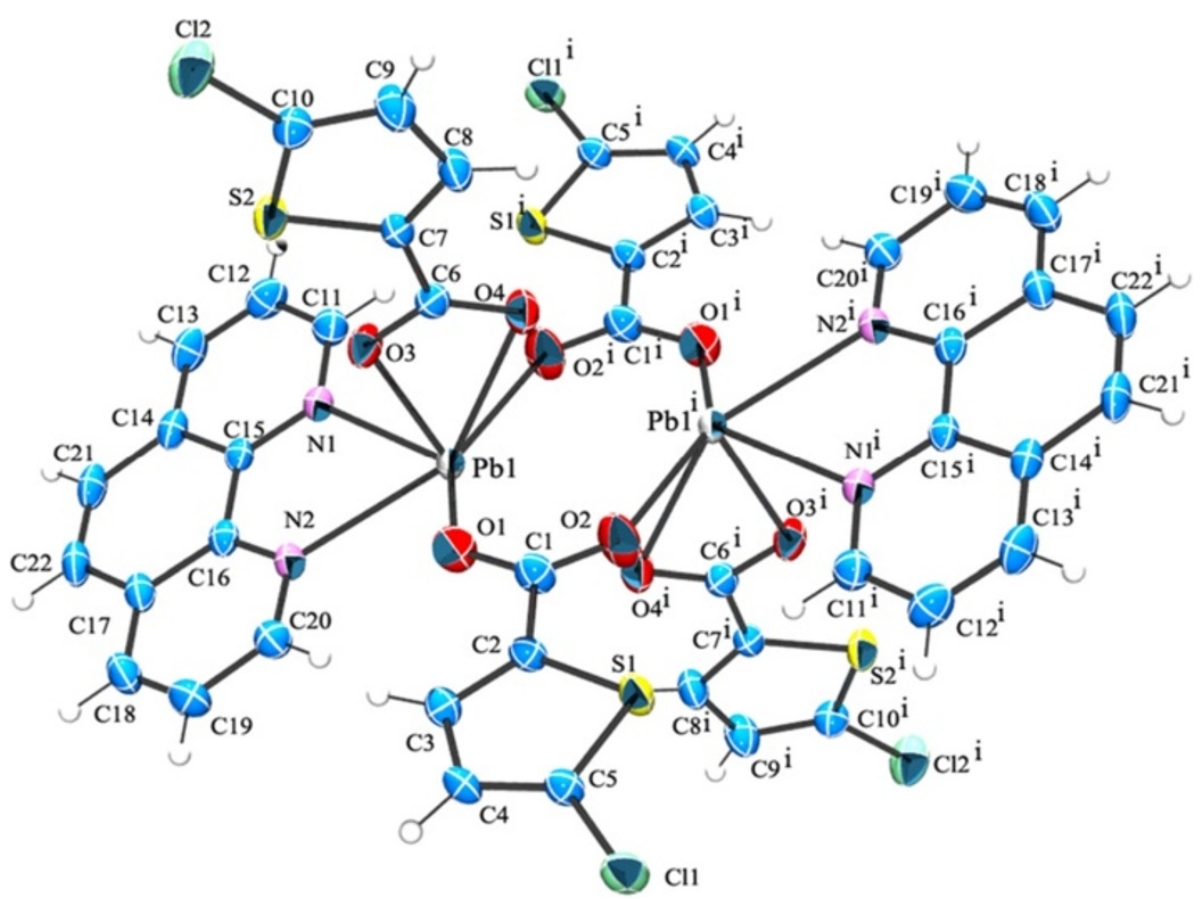

Figure 7 ORTEP of complex 3 showing the atom-numbering scheme. Displacement ellipsoids are drawn at the 50\% probability level for all non hydrogen atoms and $\mathrm{H}$ atoms are shown as small spheres of arbitrary radii.

$\mathrm{Pb}$ link). The coordination sphere of each $\mathrm{Pb}$ is completed by the bidentate chelating ligands, PHEN and 5-CTPC. The coordination around each $\mathrm{Pb}$ can be best described as capped square pyramidal geometry (Figure 1c, Figure 7).

The $\mathrm{Pb}-\mathrm{N}$ bond distances are 2.604(2) $\AA$ to 2.614(3) $\AA$, whereas the $\mathrm{Pb}-\mathrm{O}$ bond distances ranges from $2.332(2) \AA$ to $2.813(2) \AA$. Of the four oxygen atoms two are from a bidentate carboxylate of 5-CTPC and other two are bridging oxygens from two different 5-CTPC. The arrangement of the PHEN and carboxylate ligands suggests a gap coordination around the $\mathrm{Pb}(\mathrm{II})$ ion, which might be occupied by a stereoactive lone pair of electrons on $\mathrm{Pb}(\mathrm{II})$ ion and also probably due to steric hindrance of the PHEN ligand. Columns of lead atoms with $\mathrm{Pb}--\mathrm{Pb}$ separation of $3.7020(2)$ bridged by two the 5-CTPC carboxylates extend along the crystallographic a axis. The individual dimeric unit of the one layer are almost parallel to each other of the next layer and further the dimeric units are linked to each other by $\mathrm{C} 28-\mathrm{H} 28 . . \mathrm{Cl} 11^{\text {ii }}$ (Symmetry code (ii) :-2-x,-y,-z) interaction between the thiophene ring of two dimers. This interactions thus form an 8 member ring (Figure 8 ) which can be represented by the graph-set motif $\mathrm{R}_{2}^{2}(8)$ [51]. This forms a chain extending along the crystallographic a axis.

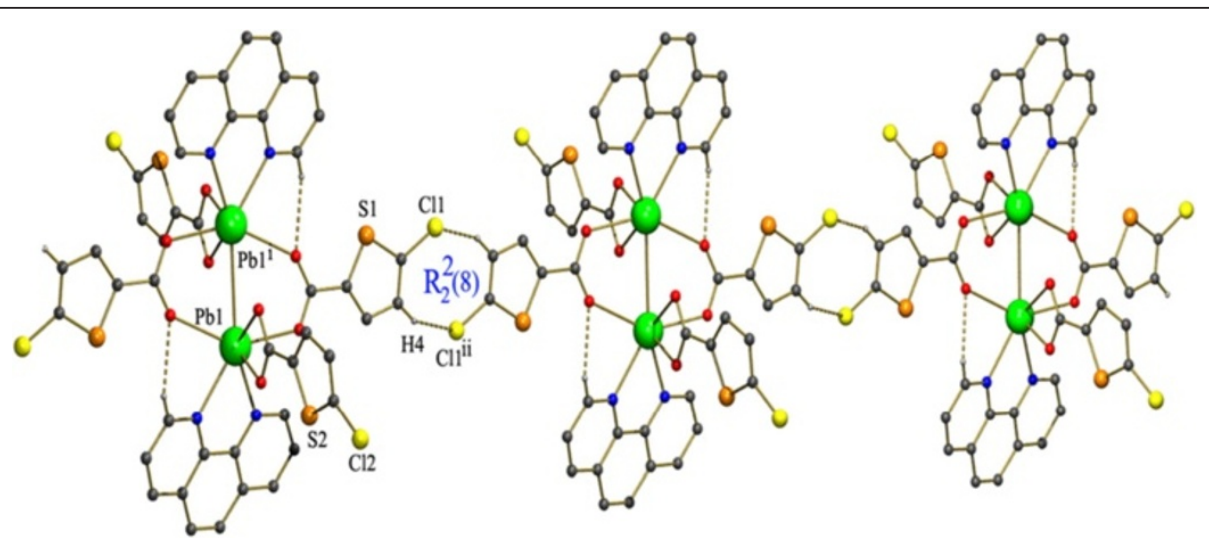

Figure 8 Hydrogen bond pattern in 3 showing the formation of $1 \mathrm{D}$ chain by $\mathbf{C}-\mathbf{H}$. Cl interactions and formation of the $\mathrm{R}_{2}^{2}(8)$ graphset motifs inbetween the individual dimeric units. 
Two of these chains are interlocked to each other by the $\pi-\pi$ stacking interactions between the two 6 membered rings made up of the nearby 1,10 phenanthroline rings $\mathrm{Cg} 5 \rightarrow \mathrm{Cg} 5^{\mathrm{iv}} \quad(\mathrm{Cg} 5=\mathrm{C} 14, \mathrm{C} 15, \mathrm{C} 16, \mathrm{C} 17, \mathrm{C} 22$ \& $\mathrm{C} 21)$ [Symmetry code (iv) :-X,2-Y,1-Z]. The $\mathrm{Cl}$ of the two thiophene rings plays a vital role in stabilisation of crystal structure, three sets of $\mathrm{Cl}$...Cg interactions are found inbetween $\mathrm{C} 5-\mathrm{Cl} 1 \ldots \mathrm{Cg} 3^{\mathrm{i}}, \mathrm{C} 5-\mathrm{Cl} 1 \ldots \mathrm{Cg} 5{ }^{\mathrm{ii}}, \mathrm{C} 10-\mathrm{Cl} 2 \ldots$ $\mathrm{Cg} 1^{\mathrm{iii}}$; where $\mathrm{Cg} 1=\mathrm{S} 1, \mathrm{C} 2-\mathrm{C} 5, \quad \mathrm{Cg} 3=\mathrm{N} 1, \mathrm{C} 11-\mathrm{C} 15$ and Cg5 = C14-C17,C22,C21 [symmetry code $\mathrm{i}=-1+\mathrm{X},-1+\mathrm{Y}$, $-1+Z$; ii = -1-X,1-Y,1-Z; iii = X,Y,1 + Z] (Figure 9). Similarly a C-H... $\pi$ interaction is found inbetween the $\mathrm{H}$ of the PHEN ligand and the five membered thiophene ring. C19-H19...Cg2 [Cg2 = S2,C7-C10 symmetry code: -1-X,1$\mathrm{Y}, 1-\mathrm{Z}]$.

This complex 3 can be structurally compared with a previously reported in the literature $\left[\mathrm{Pb}(\mathrm{TPC})_{2}(\mathrm{PHEN})\right]$ (TPC $=$ Thiophene2-carboxylic acid) [46]. It is interesting to note that the reported $\mathrm{Pb}-\mathrm{TPC}$ complex has a monomeric and these units are linked to one another by stacking and weak coordination bonds whereas complex 3 has a dinuclear unit. The only difference between the two complexes is the chloro substitution present in complex 3.

Crystal structure description of [Pb(4-BPY)(5-BTPC) 2 (4) Complexes 2 and 4 differ only by the chloro/bromo substitution in the thiophene ring. Hence they are near isomorphous with similar cell parameters (Table 3). Regarding the coordination geometry, in 4 one carboxylate is bidentate chelating while the other is in monodentate fashion. Whereas in 2 both are in bidentate fashion. Thus in 4 the $\mathrm{Pb}(\mathrm{II})$ ion is pentacoordinated, with two $\mathrm{N}$ atoms of the (4-BPY), one $\mathrm{O}$ atom of the bidentate chelating carboxylate and one $\mathrm{O}$ of the monodentate carboxylate in the basal plane and one $\mathrm{O}$ from the bidentate chelating carboxylate completing the distorted square-pyramidal geometry (Figure 10).

Although the first order coordination of 4 is different from that of 2 , the same kind of C-H...O and $\pi-\pi$ stacking interactions are found in 4 . The monomeric units are linked to each other by the $\pi-\pi$ stacking interactions in between the two five membered thiophene rings $\mathrm{Cg} 1 \rightarrow$ $\mathrm{Cg}^{\mathrm{i}}{ }^{\mathrm{C}}$ (Cg1 = S2,C7-C10) [symmetry code i: 2-X,1-Y,1-Z] . The C-H...O interactions found inbetween $\mathrm{C} 9-\mathrm{H} 9 . . . \mathrm{O} 2^{\mathrm{i}}$ [symmetry code i: $2-\mathrm{X}, 1-\mathrm{Y}, 1-\mathrm{Z}$ ]. This leads to the formation of I shaped dimer as in 2. This dimeric unit is further linked to each other to form the tetrameric unit by a pair of $\mathrm{C}-\mathrm{H}$...Br interactions (Figure 11) while these kind of interactions were absent in 2 .

Thus they form a chain. Each of these chains are further linked by the the $\pi-\pi$ stacking interactions in between the five membered thiophene rings and a $\mathrm{N}$ containing heterocyclic ring of the $4-\mathrm{BPY} \mathrm{Cg} 3 \rightarrow \mathrm{Cg}^{\text {iv }}$ $(\mathrm{Cg} 3=\mathrm{N} 1, \mathrm{C} 11-\mathrm{C} 15$ and $\mathrm{Cg} 1=\mathrm{S} 1, \mathrm{C} 2-\mathrm{C} 5)$ (Figure 12). The most unusual feature of 4 is the monodentate coordination of the carboxylate group leading to a variety of changes in the 3Dstructure. The reason for the monodentate coordination of the 5-BTPC may be attributed to the strong $\mathrm{C}-\mathrm{H} \ldots \mathrm{Br}$ and $\mathrm{C}-\mathrm{H}$...O interactions involving the 5-BTPC atoms (Figure 11).

\section{Crystal structure of description of $\left[\mathrm{Pb}_{2}(\mathrm{PHEN})_{2}(5-\mathrm{BTPC})_{2}\right.$} $\left.(\mathrm{ACE})_{2}\right](5)$

As anticipated the usage of PHEN ligand produced a dinuclear structure as 3 (Figure 13). The central $\mathrm{Pb}(\mathrm{II})$ ion not only differs in primary coordination from 3 but it is

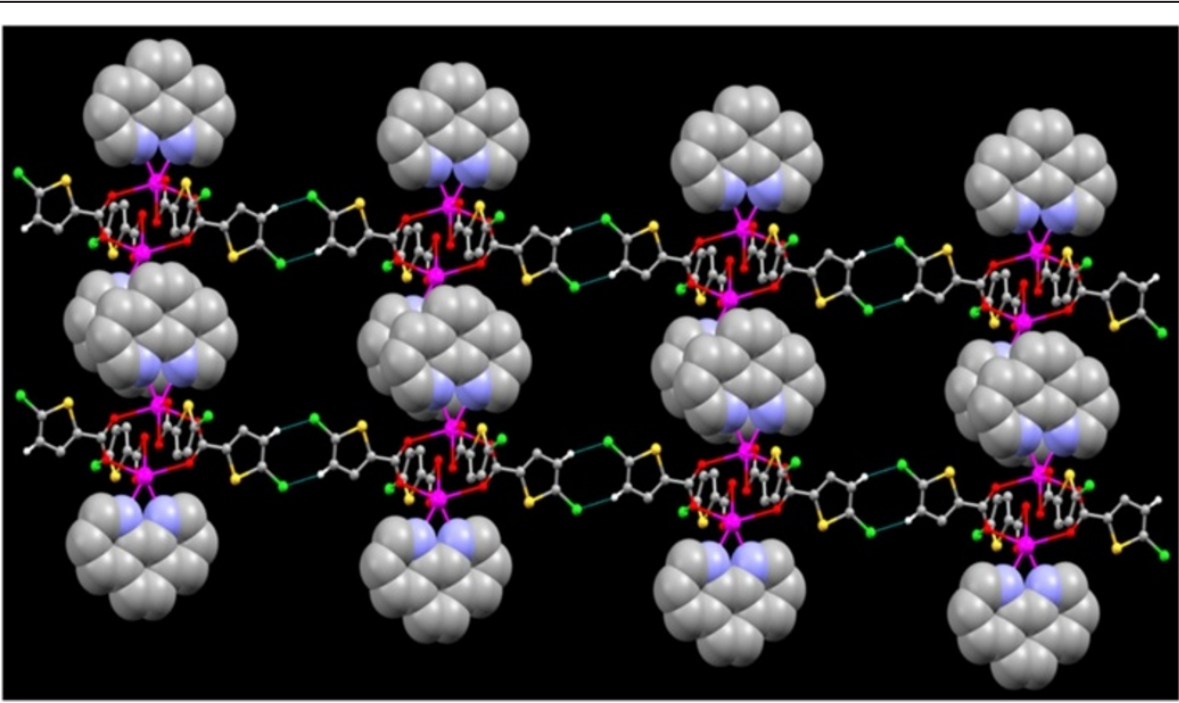

Figure 9 View of complex 3 along the crystallographic c axis showing the $\pi-\pi$ stacking interactions (spacefilled model) inbetween the 1D chains. 
Table 3 Crystal data and refinement parameters for complexes 1-5

\begin{tabular}{|c|c|c|c|c|c|}
\hline & Complex 1 & Complex 2 & Complex 3 & Complex4 & Complex5 \\
\hline Empirical formula & $\mathrm{C} 2 \mathrm{OH} 12 \mathrm{~N} 2 \mathrm{O} 4 \mathrm{Cl} 2 \mathrm{~S} 2 \mathrm{~Pb}$ & $\mathrm{C} 22 \mathrm{H} 16 \mathrm{Cl} 2 \mathrm{~N} 2 \mathrm{O} 4 \mathrm{~S} 2 \mathrm{~Pb}$ & $\mathrm{C} 44 \mathrm{H} 24 \mathrm{Cl} 4 \mathrm{~N} 4 \mathrm{O} 8 \mathrm{~S} 4 \mathrm{~Pb} 2$ & $\mathrm{C} 22 \mathrm{H} 16 \mathrm{Br} 2 \mathrm{~N} 2 \mathrm{O} 4 \mathrm{PbS} 2$ & $\mathrm{C} 38 \mathrm{H} 26 \mathrm{Br} 2 \mathrm{~N} 4 \mathrm{O} 8 \mathrm{~Pb} 2 \mathrm{~S} 2$ \\
\hline Formula weight & 686.56 & 714.61 & 1421.15 & 803.51 & 1304.97 \\
\hline Temp, K & 296 & 296 & 296 & 296 & 296 \\
\hline$\lambda(\AA)$ & 0.71073 & 0.71073 & 0.71073 & 0.71073 & 0.71073 \\
\hline Crystal system & Triclinic & Triclinic & Triclinic & Triclinic & Monoclinic \\
\hline Space group & $P-1$ & $P-1$ & $P-1$ & $P-1$ & $\mathrm{P} 21 / \mathrm{C}$ \\
\hline$a(\AA)$ & $9.0760(1)$ & 10.6261(3) & 10.2998(1) & $10.710(5)$ & $8.918(5)$ \\
\hline$b(\AA)$ & $12.0102(2)$ & $10.9835(2)$ & $11.3830(1)$ & $10.973(5)$ & $23.841(5)$ \\
\hline$c(\AA)$ & $12.0754(2)$ & $11.4710(2)$ & $11.4287(1)$ & $11.623(5)$ & $12.744(5)$ \\
\hline$a(0)$ & $116.441(1)$ & $115.441(1)$ & $100.292(1)$ & $115.592(5)$ & 90 \\
\hline$\beta\left({ }^{\circ}\right)$ & $93.682(1)$ & $98.773(1)$ & $103.011(1)$ & $98.676(5)$ & $133.39(2)$ \\
\hline$Y\left({ }^{\circ}\right)$ & 106.176(1) & $96.052(1)$ & $115.391(1)$ & $96.238(5)$ & 90 \\
\hline$V(\AA 3)$ & $1104.46(3)$ & $1172.71(5)$ & $1120.29(2)$ & 1194.5(9) & $1969.0(16)$ \\
\hline Z & 2 & 2 & 1 & 2 & 2 \\
\hline$\rho$ calcd (g/cm3) & 2.065 & 2.024 & 2.106 & 2.234 & 2.201 \\
\hline$\mu(\mathrm{mm}-1)$ & 8.099 & 7.632 & 7.989 & 10.615 & 10.732 \\
\hline$F(000)$ & 652 & 684 & 676 & 756 & 1224 \\
\hline Crystal size (mm) & $0.04 \times 0.05 \times 0.05$ & $0.05 \times 0.05 \times 0.06$ & $0.04 \times 0.05 \times 0.06$ & $0.08 \times 0.09 \times 0.06$ & $0.09 \times 0.05 \times 0.06$ \\
\hline No of reflections collected & 7170 & 8554 & 7529 & 8114 & 6592 \\
\hline Number restraints & 0 & 0 & 0 & 0 & 0 \\
\hline Goodness-of-fit on F2 & 1.026 & 1.03 & 1.00 & 1.02 & 0.98 \\
\hline Final R1 index $[I>2 \sigma(I)]$ & 0.0239 & 0.0240 & 0.0303 & 0.0290 & 0.0309 \\
\hline wR2 (all data) & 0.0541 & 0.0556 & 0.0635 & 0.0633 & 0.0690 \\
\hline $\begin{array}{l}\text { Largest difference in peak and } \\
\text { hole (e } \AA-3)\end{array}$ & $-0.61,1.14$ & $-0.63,1.27$ & $-0.45,1.18$ & $-1.08,1.13$ & $-1.05,0.88$ \\
\hline CCDC number & 821366 & 821367 & 821365 & 920520 & 920521 \\
\hline
\end{tabular}

$\mathrm{R} 1=\Sigma(|| \mathrm{Fo}|-| \mathrm{Fc}||) / \Sigma|\mathrm{Fo}| ; \mathrm{wR} 2=[\Sigma \mathrm{w}(|\mathrm{Fo}|-|\mathrm{Fc}| 2) 2] / \Sigma \mathrm{w}(|\mathrm{Fo}| 2)] 1 / 2$.

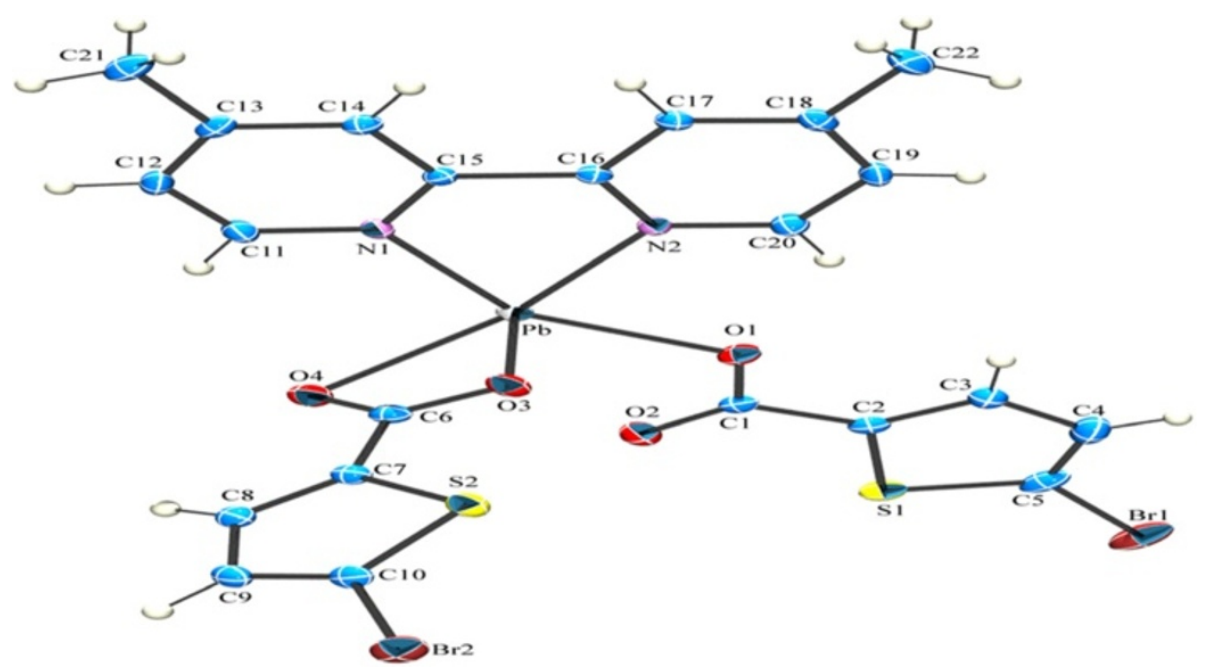

Figure 10 ORTEP of complex 4 showing the atom-numbering scheme. Displacement ellipsoids are drawn at the 50\% probability level for all non hydrogen atoms and $\mathrm{H}$ atoms are shown as small spheres of arbitrary radii. 


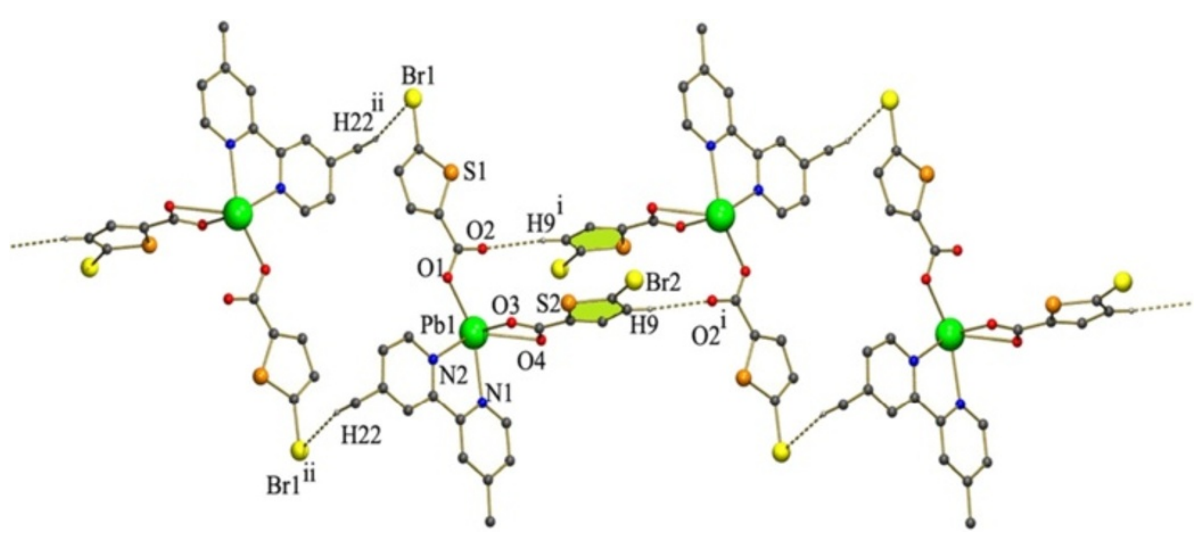

Figure 11 1D H-bonded chain formed by C-H...Br, C-H...O and $\pi-\pi$ stacking interactions existing in 4.

entirely different from all the above structures. Each of the $\mathrm{Pb}$ (II) ion is coordinated to a PHEN and 5-BTPC in a bidentate chelating mode. Unlike the complex 3 the bridging carboxylate is replaced by chelating bridging acetate group of the starting material. This is also expected as the increase in $\mathrm{Pb}$...Pb separation of 4.482 (3) $\AA$ compared with that of 3 .

The expected $\mathrm{C}-\mathrm{H} . . . \mathrm{Br}$ and $\mathrm{Br}$...Cg interactions are absent since one of the carboxylate has been replaced by the acetate group (Figure 14). The less steric hindrance of the acetate group made it possible for the $\mathrm{C}-\mathrm{H}$...O interaction inbetween $\mathrm{H}$ of the PHEN ring and $\mathrm{O}$ of the acetate group (C15-H15...O22 ${ }^{\text {ii }}$ [symmetry code ii: $\left.\left.2-\mathrm{x}, 1-\mathrm{y}, 2-\mathrm{z}\right]\right)$. Also as expected the chains formed by the $\mathrm{C}-\mathrm{H}$... Cl interactions (Figure 8) in the case of 3 is absent here. Further the individual dinuclear units are linked by the $\pi-\pi$ stacking interactions are found in between the two 6 membered rings of the nearby PHEN rings $\mathrm{Cg} 5 \rightarrow \mathrm{Cg} 5{ }^{\mathrm{ii}}(\mathrm{Cg} 5=\mathrm{N} 2, \mathrm{C} 13-\mathrm{C} 17)$ [Symmetry code (ii): 2-x,1-y,2-z]. These C-H...O and $\pi-\pi$ stacking interactions extend along the crystallographic $\mathrm{c}$ axis leading to formation of a chain.

Two of these adjacent chains are interlinked by $\mathrm{C}-\mathrm{H} \ldots$ $\mathrm{Cg}$ interactions inbetween the $\mathrm{H}$ of PHEN ring of a chain and five membered thiophene ring of the adjacent chain [C10-H10...Cg1 $1^{\text {ii }}$ symmetry code ii: $\left.2-\mathrm{X}, 1 / 2+\mathrm{Y}, 3 / 2-\mathrm{Z}\right]$ (Figure 15).

\section{Involvement of $\mathrm{X}(\mathrm{X}=\mathrm{Cl}, \mathrm{Br})$ in interactions}

Amid other non covalent interactions involving hetero atoms the role of $\mathrm{Cl} \cdots \pi, \mathrm{C}-\mathrm{H} \cdots \pi$, \& $\mathrm{Br} \cdots \pi$ have been given importance due to their role in lattice stabilization and their contribution in determining the modes of packing in a molecular packing and in solid state it can never be over looked [52]. The non covalent interactions involving

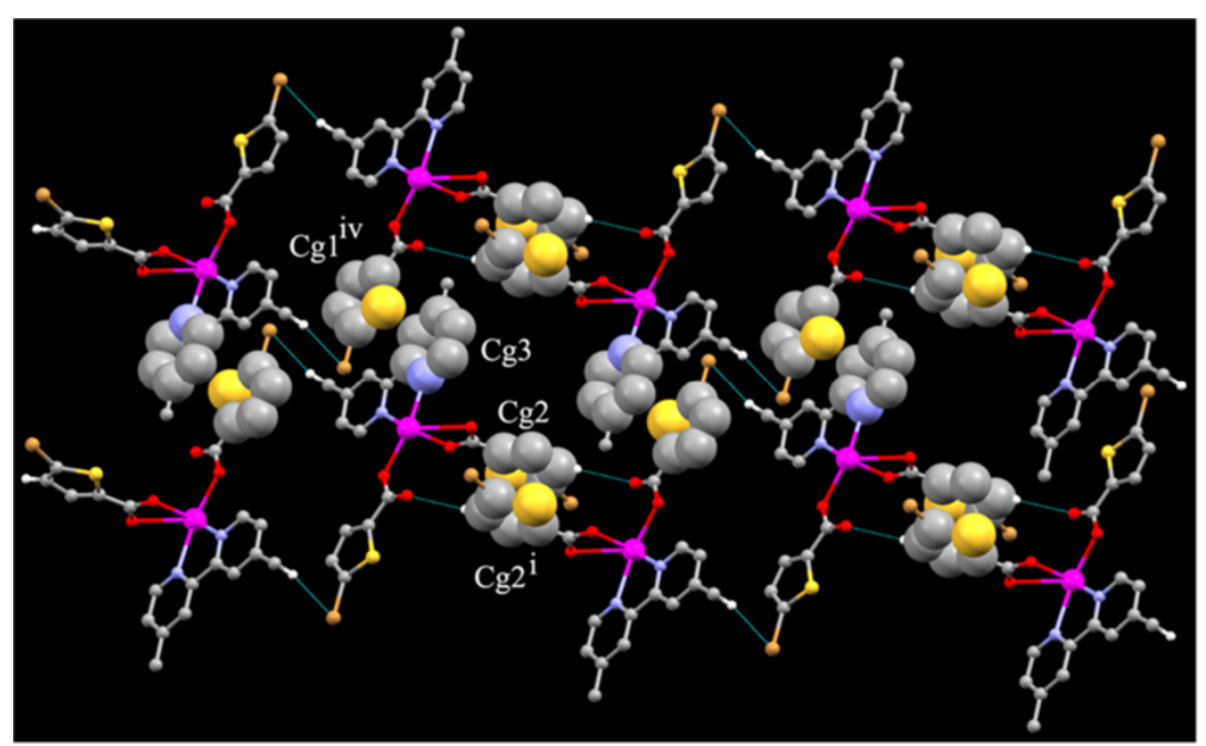

Figure 12 Crystal packing in 4 the rings involved in stacking interactions are shown as spacefilled models. 


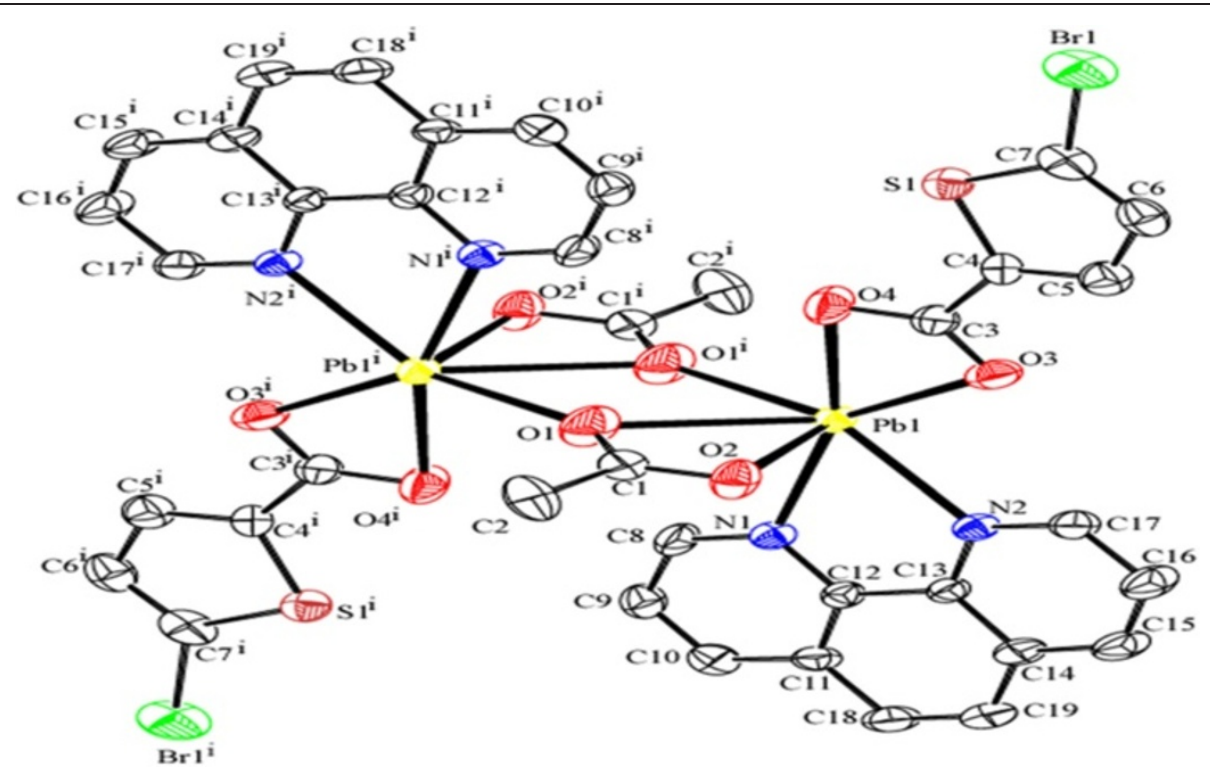

Figure 13 ORTEP of complex 5 showing the atom-numbering scheme. Displacement ellipsoids are drawn at the 50\% probability level for all non hydrogen atoms and $\mathrm{H}$ atoms are shown as small spheres of arbitrary radii.

halogen fall in four types as given in (Figure 16a-d). The geometry of this $\mathrm{R}-\mathrm{H}$...X interaction play a major role in predictability of these interactions. In this backdrop it is worth in mentioning that we have studied various non covalent interactions involving the halogen atom in complexes 1-5 and the results are given in (Table 4). Various $\theta 1$ values have been observed with the highest $\mathrm{C}-\mathrm{Cl} \cdots \pi \mathrm{r}$ for complex 1. Previous reports state that an interaction of the type $\mathrm{H}$...X. $\mathrm{C}$ the preferred angle would be in the range of $90-130^{\circ}$ rather than higher angles $[53,54]$. The observed $\theta 2$ values agree well with the above survey.
Repeating metal bite unit comprised of $\mathrm{PbC}_{2} \mathrm{~N}_{2}$ in (1-5)

The metal bite $\left(\mathrm{PbN}_{2} \mathrm{C}_{2}\right)$ unit is the repeating common unit of 1-5. This metal bite in 1 is formed with two coordinating $\mathrm{N}$ atoms, two carbon atoms of the BPY and the central lead atom, while in 2,4 it is formed by two coordinating $\mathrm{N}$ atoms, two carbon atoms of the 4-BPY and the central lead atom. While in 3,5 it is formed with two coordinating $\mathrm{N}$ atoms, two carbon atoms of the PHEN and the central lead atom.

The metal bite is a monomeric unit in 1,2 and 4 while it is dimeric in 3,5. In 3 the metal bites are separated by a

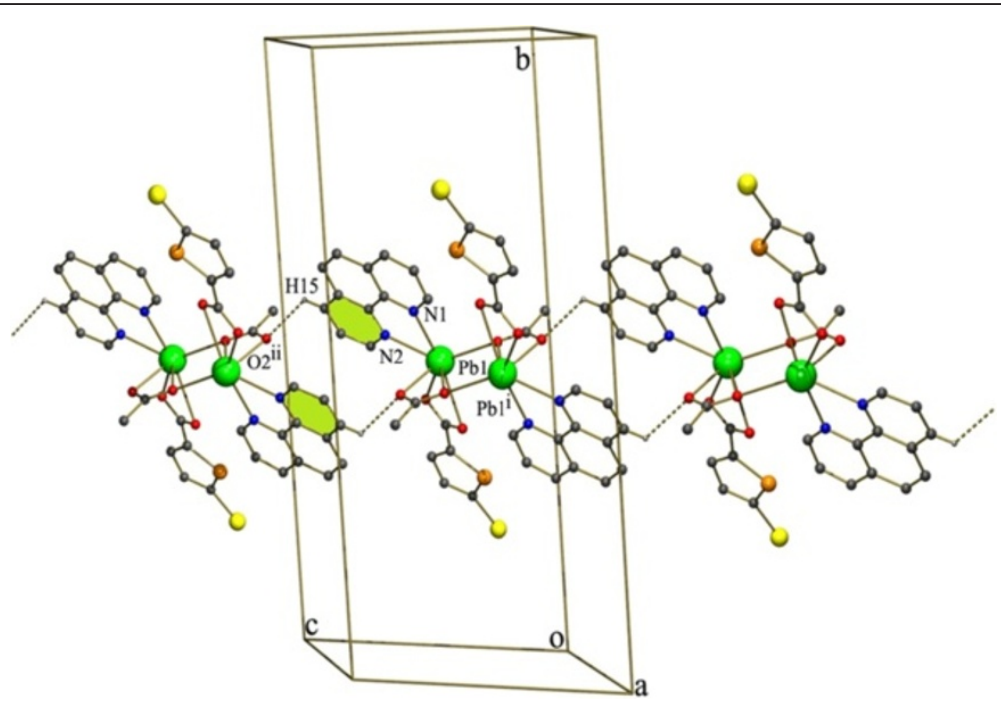

Figure $14 \mathrm{H}$-bonded chain formed by $\mathrm{C}-\mathrm{H} . . . \mathrm{O}$ and $\pi-\pi$ stacking interactions existing in complex 5 . 


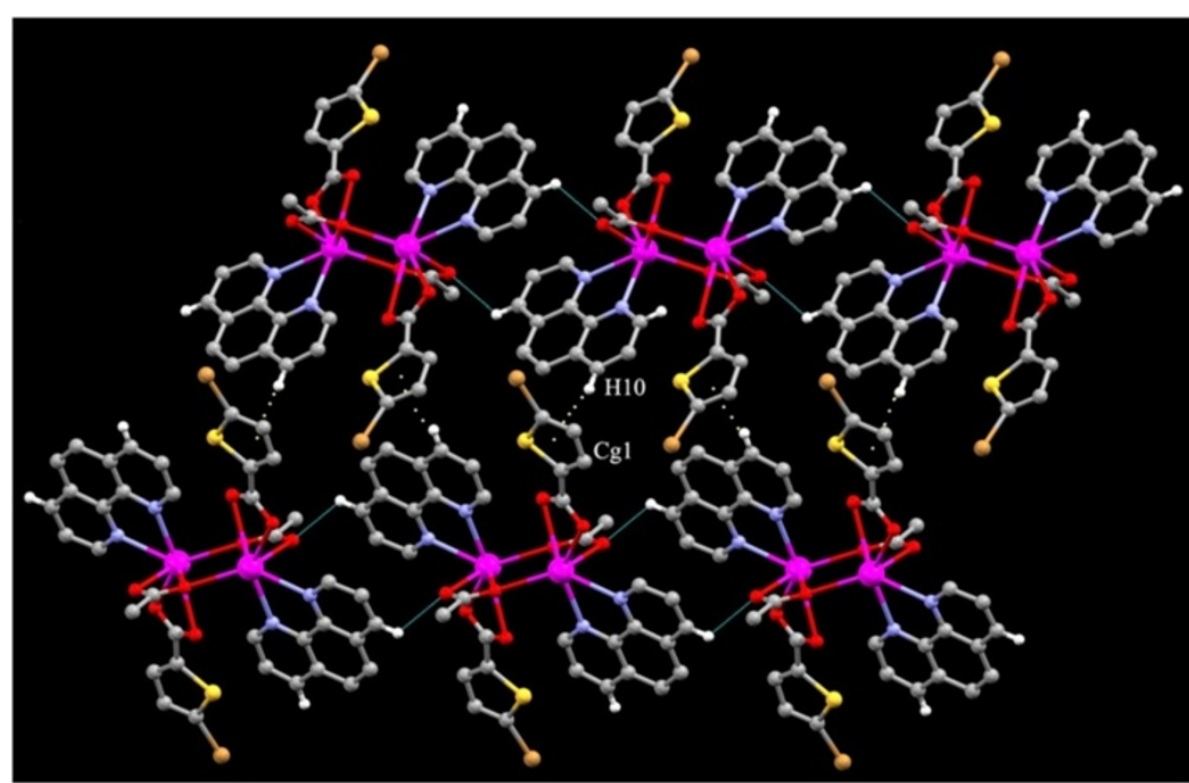

Figure 15 Perspective view of 5 the C-H... interactions shown as dotted lines.

distance of 3.702(2) $\AA$. While in 5 the metal bites are bridged by one of the carboxylate oxygen atoms. Interestingly the bond angles and bond lengths of the metal bite 1,2 and 4 as well as 3 and 5 are almost comparable in complexes (Figure 17a,b,d) and (Figure 17c,e) respectively. On seeing the packing arrangement of these metal bite units, they are self assembled irrespective of whether they are monomeric in 1, 2 and 4 or dimeric in 3, 5. A view of the metal bites is shown in (Figure 18a-e). The dihedral angles between the two pyridine rings in 1,2 and 4 are $4.69(15), 1.23(12)^{\circ}$ and $1.43(15)^{\circ}$ respectively. This shows that the planarity of BPY, 4-BPY and PHEN is maintained.

\section{Thermal analysis}

Thermogravimetric analysis (TGA) experiments of the complexes 1-5 were conducted under a static atmosphere of nitrogen at temperatures ranging from RT (room temperature) to $1000^{\circ} \mathrm{C}$ in order to determine the thermal stabilities (Additional file 1). Due to similarities of 1,2, 4 and 3, 5 they show similar decomposition patterns (Figure 19). The complexes 1-5 started to melt well above $150^{\circ} \mathrm{C}$ showing a very small thermal effect. Complexes 1, 2, 4 showed two steps of thermal decomposition at $\left(148-430^{\circ} \mathrm{C}, 150-540^{\circ} \mathrm{C}, 168-662^{\circ} \mathrm{C}\right)$ which probably due to two 5-TPC ligands. The decomposition of the

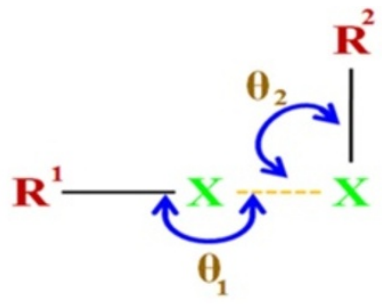

a

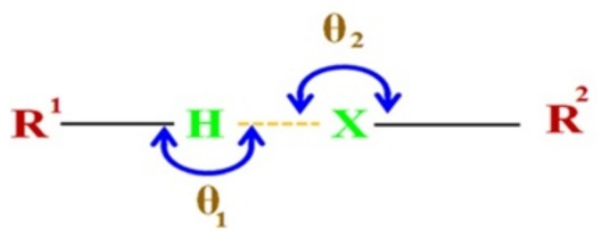

C

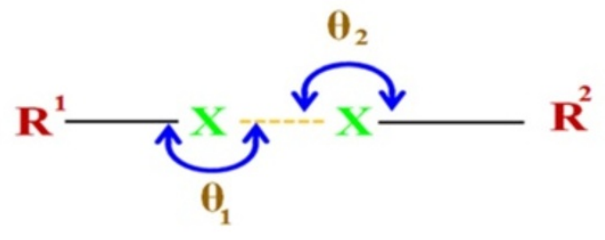

b

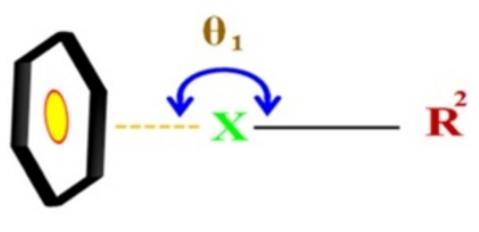

d

Figure 16 Various possible noncovalent interactions involving the halide, in (a) $\theta 1=\theta 2 \neq 90$; (b) $\theta 1=\theta 2=90$ and $(c, d)$ other possible interations. 
Table 4 Bond metrics for $\mathrm{X}(\mathrm{X}=\mathrm{Cl}, \mathrm{Br})$ involved non covalent interactions in complexes 1-5

\begin{tabular}{|c|c|c|c|c|c|c|}
\hline \multirow{2}{*}{$\frac{\text { Complex }}{1}$} & \multirow{2}{*}{$\begin{array}{l}\text { Presence of } \mathrm{X}(\mathrm{X}=\mathrm{Cl}, \mathrm{Br}) \text { involved non covalent interactions } \\
\qquad \sqrt{ }\end{array}$} & \multicolumn{2}{|c|}{ Type of interaction } & \multirow{2}{*}{$\begin{array}{l}\text { Distance in } \AA \\
3.5167 \text { (19) }\end{array}$} & \multirow{2}{*}{$\begin{array}{l}\boldsymbol{\theta 1}\left(^{\circ}\right) \\
173.61(15)\end{array}$} & \multirow[t]{2}{*}{$\theta 2\left(^{\circ}\right)$} \\
\hline & & (d) $C-C \mid \cdots \pi$ & $\mathrm{C} 5-\mathrm{Cl} 1 \cdots \mathrm{Cg} 3$ & & & \\
\hline 2,5 & Not involved & & & & & \\
\hline \multirow[t]{4}{*}{3} & $\sqrt{ }$ & (c) $\mathrm{C}-\mathrm{H} \cdots \mathrm{Cl}$ & $\mathrm{C} 4-\mathrm{H} 4 \cdots \mathrm{Cl} 1$ & 2.81 & 146.42 & 130.75 \\
\hline & & (d) $C-C \mid \cdots \pi$ & $\mathrm{C} 5-\mathrm{Cl} 1 \cdots \mathrm{Cg} 3$ & $3.8566(18)$ & $93.99(12)$ & \\
\hline & & (d) $C-C \mid \cdots \pi$ & $\mathrm{C} 5-\mathrm{Cl} 1 \cdots \mathrm{Cg} 5$ & $3.9010(18)$ & $65.46(12)$ & \\
\hline & & (d) $\mathrm{C}-\mathrm{Cl} \cdots \pi$ & $\mathrm{C} 10-\mathrm{Cl} 2 \cdots \mathrm{Cg} 1$ & $3.8632(19)$ & $131.18(15)$ & \\
\hline \multirow[t]{2}{*}{4} & $\sqrt{ }$ & (c) $\mathrm{C}-\mathrm{H} \cdots \mathrm{Br}$ & $\mathrm{C} 22-\mathrm{H} 22 \mathrm{~A} \cdots \mathrm{Br} 1$ & 2.8700 & 162.19 & 71.83 \\
\hline & & (d) $C-B r \cdots \pi$ & $C(5)-B r(1) \cdots C g(4)$ & $3.462(2)$ & 86.36(13) & \\
\hline
\end{tabular}

bipyridine ligands took place at $\left(435-957^{\circ} \mathrm{C}, 545-745^{\circ} \mathrm{C}\right.$, $667-842^{\circ} \mathrm{C}$ ) in 1,2 and 4 respectively. Complexes 3,5 exhibit their first weight loss at temperature ranges of $\left(145-405^{\circ} \mathrm{C}\right.$ and $\left.212-497^{\circ} \mathrm{C}\right)$. This is due to loss of four 5 -TPC molecules in 3 as well as two 5-TPC molecules and two ACE molecules in 5. The second stage of decomposition at $\left(416-848^{\circ} \mathrm{C}, 501-733^{\circ} \mathrm{C}\right)$ in 3 and 5 respectively are due to the decomposition of PHEN ligands.

\section{Photoluminiscent properties}

Previous studies show that $\mathrm{Pb}(\mathrm{II})$ complexes constructed with conjugated organic ligands can act as potential candidates for photoactive materials with appealing photoluminescence properties. Therefore, solidstate photo luminescence properties of $\mathrm{Pb}(\mathrm{II})$ complexes $1-5$, with that of $\mathrm{N}, \mathrm{N}^{\prime}$ chelating ligand, were investigated at room temperature based on their UV-vis spectra

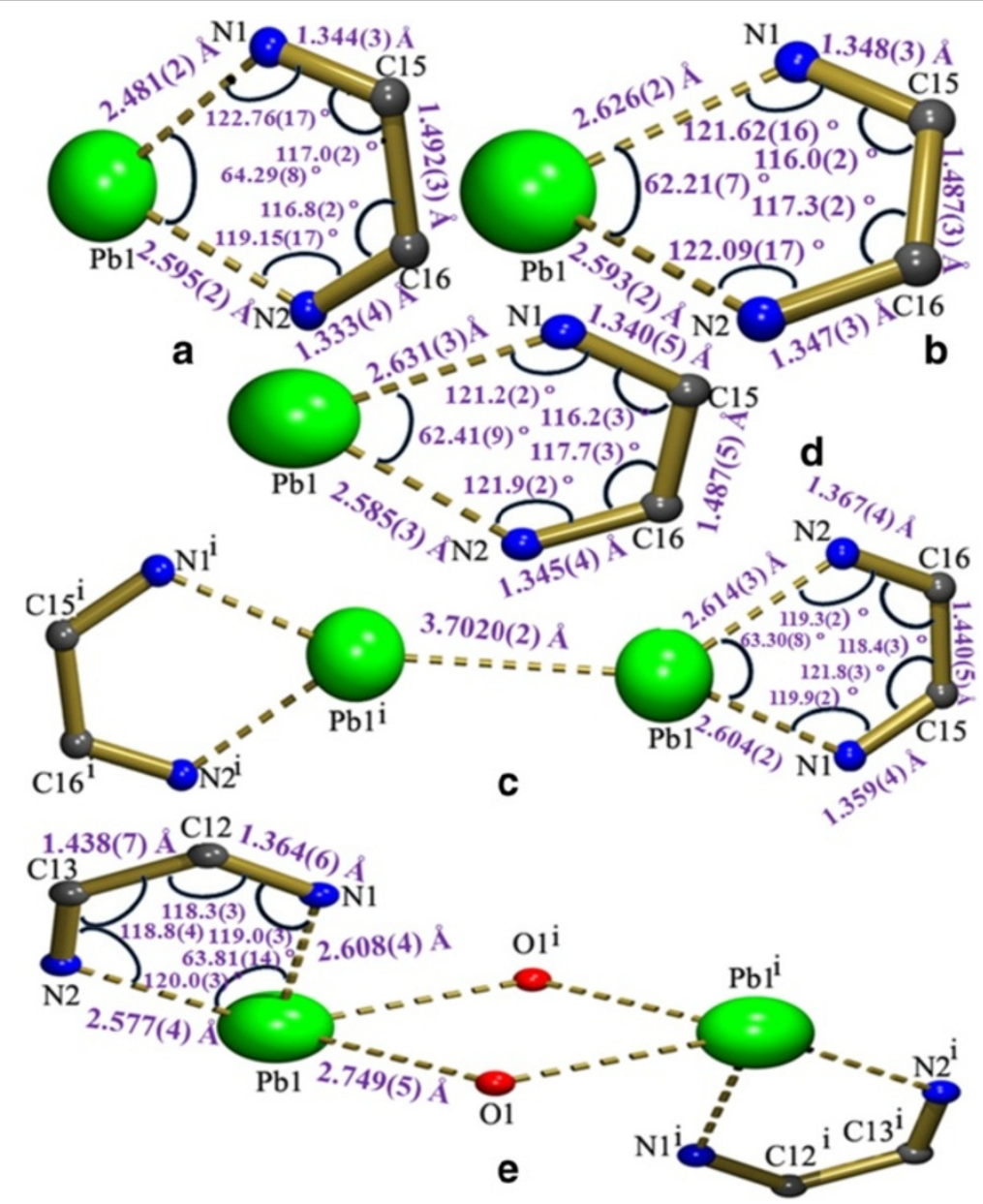

Figure 17 Showing the metal bite which is the repeating. (a) Complex 1; (b) Complex 2; (c) Complex 3; (d) Complex 4 and (e) Complex 5. 


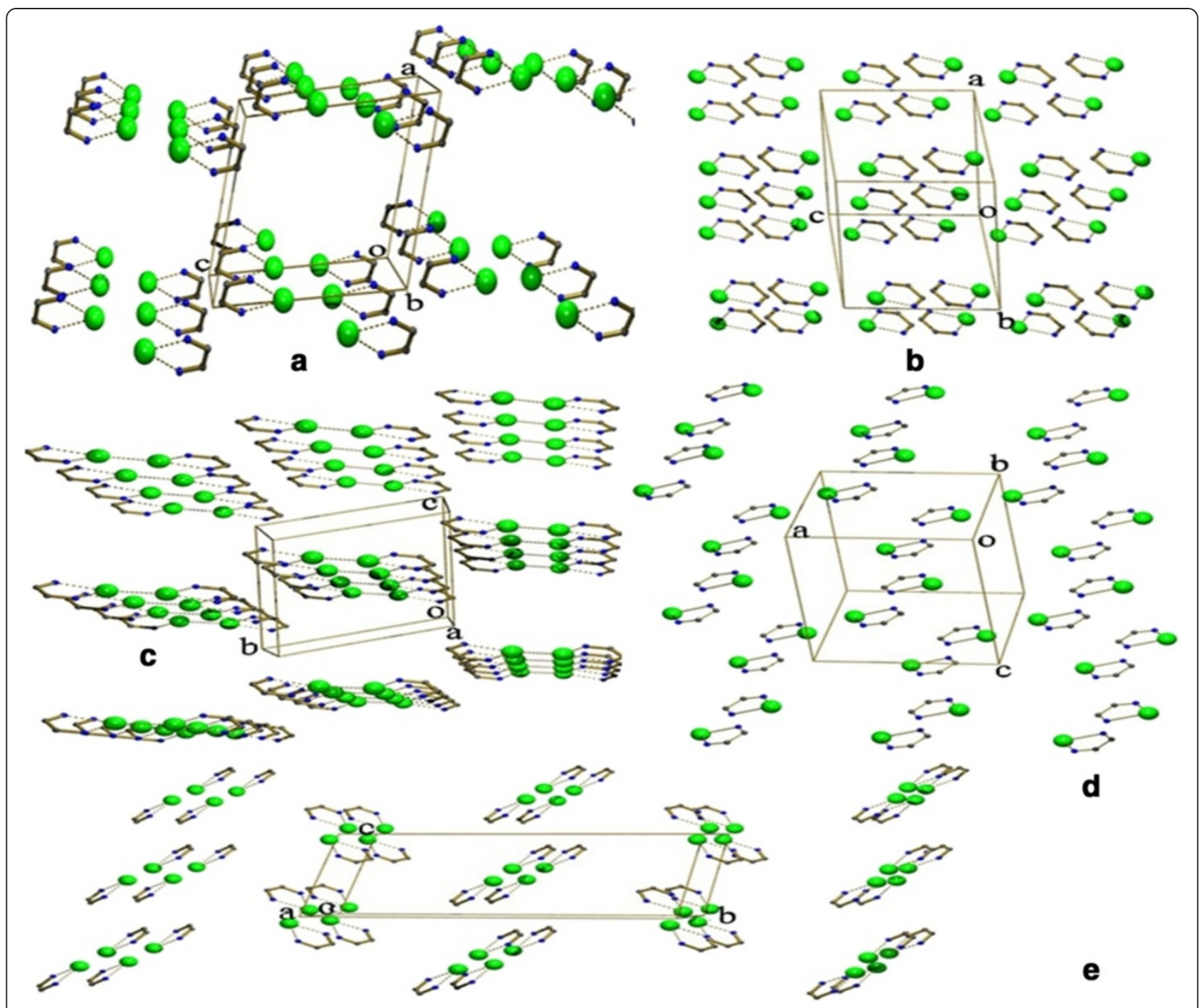

Figure 18 The self assembly of the metal bites generating supramolecular architecture. (a) Complex 1; (b) Complex 2; (c) Complex 3; (d) Complex 4 and (e) Complex 5

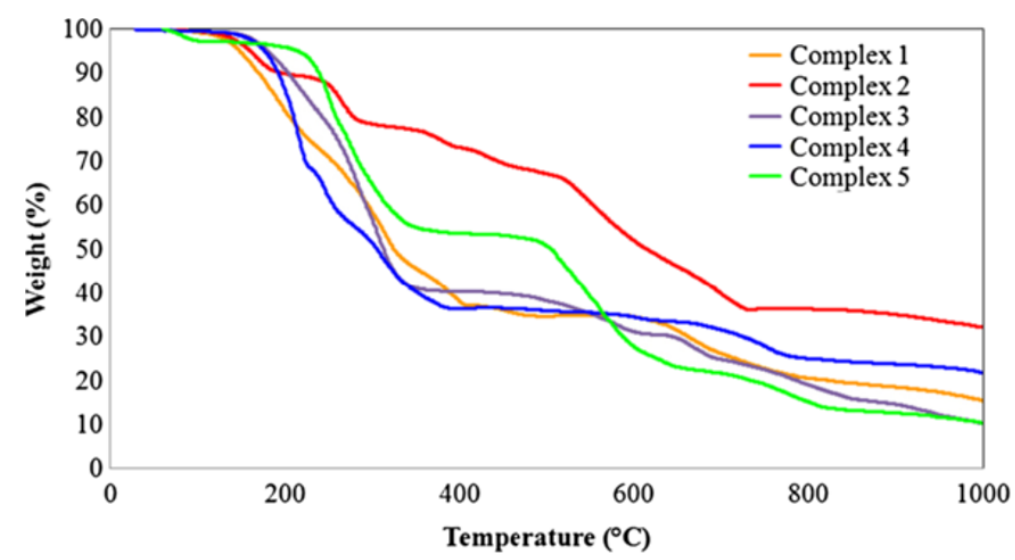

Figure 19 Thermograms of complexes 1-5 showing TGA curves at the heating rate of $10^{\circ} \mathrm{C} / \mathrm{min}$. 
(Figure 20). The complex 1 displays a fluorescent emission at $538 \mathrm{~nm}\left(\lambda_{\mathrm{ex}}=423 \mathrm{~nm}\right), 2$ at $527 \mathrm{~nm}\left(\lambda_{\mathrm{ex}}=436 \mathrm{~nm}\right), 3$ at $547 \mathrm{~nm}\left(\lambda_{\mathrm{ex}}=441 \mathrm{~nm}\right), 4$ at $540 \mathrm{~nm}\left(\lambda_{\mathrm{ex}}=429 \mathrm{~nm}\right)$ and 5 at $551 \mathrm{~nm}\left(\lambda_{\mathrm{ex}}=443 \mathrm{~nm}\right)$. The intense emission bands of complexes 1-5 to their corresponding ligands implies that the emission peaks of 1-5 may be due to a metal-toligand charge transfer (MLCT) and/or ligand-to-metal charge transfer (LMCT). Hence complexes 1-5 may serve as potential organic-inorganic hybrid photoactive materials [55].

\section{Experimental}

\section{Materials and methods}

Commercial starting materials were used without further purification. 2,2'bipyridine (Aldrich), 4,4' -dimethyl-2,2' -bipyridine (Aldrich), 5-Chlorothiophen-2carboxylic acid (Hoechst Aktiengesellschaft), methanol (Qualigens, India), 5-Bromothiophene-2-carboxylic acid (Aldrich), $\mathrm{Pb}\left(\mathrm{CH}_{3} \mathrm{COO}\right)_{2} \cdot 3 \mathrm{H}_{2} \mathrm{O}$ were used. IR spectra of the complex in region $400-4000 \mathrm{~cm}^{-1}$ were recorded as pressed disks ( $1 \%$ by weight in $\mathrm{KBr}$ ) on a Shimadzu FT IR spectrophotometer (Additional file 1). ${ }^{1} \mathrm{H}-\mathrm{NMR}$ and ${ }^{13} \mathrm{C}-\mathrm{NMR}$ spectra were recorded with a Bruker spectrometer at $400 \mathrm{MHz}$ in [D6] DMSO (Additional file 1). CHNS analysis was carried out using Elementar Vario EL III in solid state (Table 5). The fluorescent properties were studied in solid state on a HITACHI spectrofluorimeter in solid state at room temperature. Both the excitation slit and emission slit were $5 \mathrm{~nm}$. Thermal stability studies were carried out on a STA 409 PL Luxx thermal analyzer at a heating rate of $10^{\circ} \mathrm{C} / \mathrm{min}$ under nitrogen atmosphere.
Synthesis of $\left[\mathrm{Pb}(\mathrm{BPY})(5-\mathrm{CTPC})_{2}\right]$ (1)

A solution of $\mathrm{Pb}\left(\mathrm{CH}_{3} \mathrm{COO}\right)_{2} \cdot 3 \mathrm{H}_{2} \mathrm{O}(0.098 \mathrm{~g})$ in $10 \mathrm{ml}$ of (1:1) $\mathrm{CH}_{3} \mathrm{OH} / \mathrm{H}_{2} \mathrm{O}$ mixture was stirred over a hot plate magnetic stirrer for half an hour and 5-CTPC (0.0833 g) dissolved in $10 \mathrm{ml}$ of $\mathrm{CH}_{3} \mathrm{OH}$ was added to it. The mixture was stirred for an additional of 2 hours. A yellow coloured solution was formed. About (0.0442 g) of (2-2'-bipyridine) was dissolved in $10 \mathrm{ml}$ of hot water and added to the reaction mixture; to this solution about $(5 \mathrm{ml})$ of glacial acetic acid was added. The mixture was stirred for 3 hours (Scheme 2). The dirty white precipitate was filtered off and the resulting pale yellow solution was kept for slow evaporation. Crystals were deposited at room temperature from the saturated solution. After 3 days, pale yellow coloured crystals suitable for X-ray diffraction were obtained. The crystals were filtered and washed with small portions of methanol and were dried in air (yield 75\% based on $\mathrm{Pb})$. IR selected bands $\left(\mathrm{cm}^{-1}\right): 1685(\mathrm{~s}), 1560(\mathrm{~s})$, 1431(s), 1107(s), 994(s), 842(s), 794(s), 762(s), 723(s), 513 (m). ${ }^{11} \mathrm{H}$ NMR (400 MHz, DMSO): $\delta 9.32$ (d, $J=4.8 \mathrm{~Hz}$, $1 \mathrm{H}), 8.69$ (d, $J=6.4 \mathrm{~Hz}, 2 \mathrm{H}), 8.38(\mathrm{~d}, J=10.0 \mathrm{~Hz}, 1 \mathrm{H})$, $8.11(\mathrm{~s}, 1 \mathrm{H}), 7.95-7.94(\mathrm{~m}, 2 \mathrm{H}), 7.45(\mathrm{t}, 1 \mathrm{H}), 7.28(\mathrm{~d}$, $J=4 \mathrm{~Hz}, 2 \mathrm{H}), 7.08(\mathrm{~d}, J=4.0 \mathrm{~Hz}, 2 \mathrm{H}) \mathrm{ppm} ;{ }^{13} \mathrm{C} \mathrm{NMR}$ (100 MHz, DMSO): $\delta$ 166.3, 155.2, 150.0, 149.2, 144.9, $144.1,137.7,137.3,131.3,129.5,129.3,127.7,127.0$, 124.22, 124.17, $120.4 \mathrm{ppm}$.

\section{Synthesis of $\left[\mathrm{Pb}(4-\mathrm{BPY})(5-\mathrm{CTPC})_{2}\right](2)$}

The structure of complex (1) inspired us to design the preparation of complex (2) with same chelating mode using the 4,4'-dimethyl-2,2'-bipyridine ligand. The

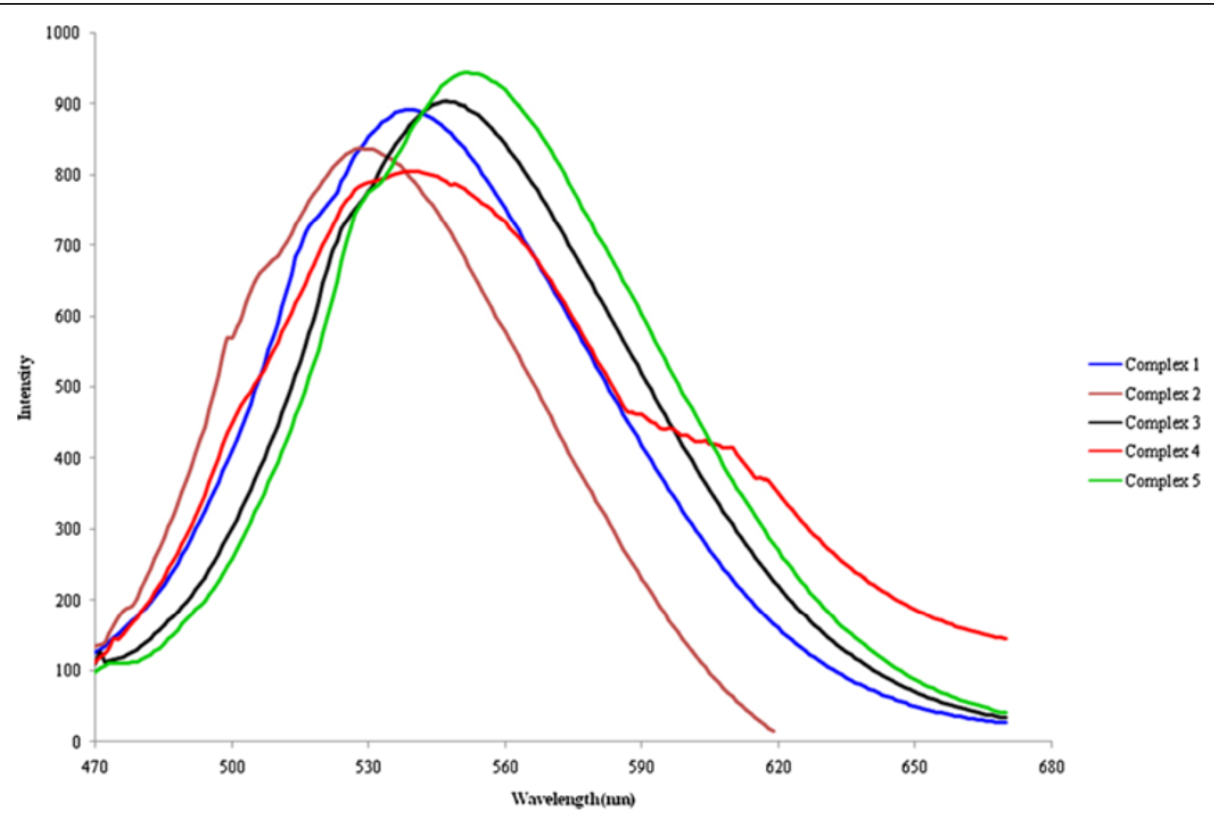

Figure 20 Solid-state emission spectra of complexes 1-5. 
Table 5 Color, elemental analyses and stoichiometries of the Lead(II) complexes

\begin{tabular}{|c|c|c|c|c|c|}
\hline \multirow[t]{2}{*}{ Complex } & \multirow[t]{2}{*}{ Color } & \multicolumn{4}{|c|}{ Found (calculated) (\%) } \\
\hline & & $\mathrm{C}$ & $\mathrm{H}$ & $\mathbf{N}$ & $S$ \\
\hline \multirow[t]{2}{*}{ [Pb(BPY)(5-CTPC)2] } & Pale yellow & 35.12 & 2.25 & 4.19 & 9.03 \\
\hline & & $(34.89)$ & $(2.05)$ & $(4.07)$ & $(9.31)$ \\
\hline \multirow[t]{2}{*}{ [Pb(4-BPY)(5-CTPC)2] } & Pale yellow & 36.50 & 2.85 & 3.95 & 8.89 \\
\hline & & $(36.87)$ & $(2.53)$ & (3.91) & (8.95) \\
\hline \multirow[t]{2}{*}{ [Pb2(PHEN)2(5-CTPC)4] } & Yellow & 37.58 & 1.96 & 3.85 & 9.03 \\
\hline & & $(37.08)$ & $(1.98)$ & (3.93) & $(9.00)$ \\
\hline \multirow[t]{2}{*}{ [Pb(4-BPY)(5-BTPC)2] } & Yellow & 32.95 & 2.25 & 3.55 & 8.00 \\
\hline & & $(32.84)$ & $(2.13)$ & (3.48) & $(7.97)$ \\
\hline \multirow[t]{2}{*}{ [Pb2(PHEN)2(5-BTPC)2(ACE)2] } & Pale yellow & 34.82 & 2.38 & 4.65 & 4.80 \\
\hline & & $(34.87)$ & $(2.31)$ & $(4.28)$ & $(4.90)$ \\
\hline
\end{tabular}

procedure of preparation of (2) is similar to (1). Instead of 2-2'-bipyridine, 4,4' -dimethyl-2,2'-bipyridine was used (Scheme 2) (yield $62 \%$ based on $\mathrm{Pb}$ ). IR selected bands $\left(\mathrm{cm}^{-1}\right)$ : $3435(\mathrm{~m}), 1432(\mathrm{~s}), 1387(\mathrm{~s}), 1310(\mathrm{~m}), 1108(\mathrm{~m})$, 1056(m), 996(s), 921(s), 835(s), 798(s), 767(s), 513(m), ${ }^{1} \mathrm{H}$ NMR (400 MHz, DMSO): $\delta 8.53$ (d, J=4.8 Hz, $2 \mathrm{H}), 8.22$ (s, $2 \mathrm{H}), 7.32-7.27(\mathrm{~m}, 4 \mathrm{H}), 7.11(\mathrm{~s}, 2 \mathrm{H}), 2.40(\mathrm{~s}, 6 \mathrm{H})$ ppm; ${ }^{13} \mathrm{C}$ NMR (100 MHz, DMSO): $\delta$ 166.4, 155.0, 148.9, 147.9, 144.0, 131.5, 129.7, 127.7, 124.9, 121.3, 20.7 ppm.
Synthesis of $\left[\mathrm{Pb}_{2}(\mathrm{PHEN})_{2}(5-\mathrm{CTPC})_{4}\right]$ (3)

The structures of complexes (1) and (2) inspired us to design the preparation of compound (2) with same chelating mode using 1,10-phenanthroline ligand. The procedure of preparation of (3) is similar to that of (1). Instead of 2-2'-bipyridine, 1,10-phenanthroline was used (Scheme 2) (yield $70 \%$ based on $\mathrm{Pb})$. IR selected bands $\left(\mathrm{cm}^{-1}\right): 3047(\mathrm{~m})$, 1557(s), 1372(s), 1205(m), 1138(s), 1105(s), 1055(s), 994(s), 860(s), 843(s), 798(s), 767(s), 725(s), 666(s), 511(m). ${ }^{1} \mathrm{H}$ NMR (400 MHz, DMSO): $\delta 9.20$ (d, J=5.6 Hz, $2 \mathrm{H}$ ), 8.59 $(\mathrm{d}, J=9.6 \mathrm{~Hz}, 2 \mathrm{H}), 8.04$ (s, $2 \mathrm{H}), 7.90-7.87$ (m, $2 \mathrm{H}), 7.33$ $(\mathrm{d}, J=3.6 \mathrm{~Hz}, 1 \mathrm{H}), 7.06(\mathrm{~d}, J=4.0 \mathrm{~Hz}, 1 \mathrm{H}) \mathrm{ppm} ;{ }^{13} \mathrm{C} \mathrm{NMR}$ (100 MHz, DMSO): $\delta$ 163.8, 149.9, 145.2, 136.9, 132.7, 131.0, 128.8, 127.9, 126.8, 123.7 ppm.

\section{Synthesis of $\left[\mathrm{Pb}(4-\mathrm{BPY})(5-\mathrm{BTPC})_{2}\right](4)$}

The procedure of preparation of (4) is similar to (2). Instead of 5-CTPC, 5-BTPC was used (Scheme 2) (yield 53\% based on $\mathrm{Pb})$. IR selected bands $\left(\mathrm{cm}^{-1}\right)$ : 1591(s), 1418(s), 990(s), 825(s), 764(s), 681(s), 514(s), . ${ }^{1} \mathrm{H}$ NMR (400 MHz, $\left.\mathrm{CDCl}_{3}\right): \delta 8.56(\mathrm{~d}, J=4.8 \mathrm{~Hz}, 1 \mathrm{H}), 8.21(\mathrm{~s}, 1 \mathrm{H}), 7.15(\mathrm{~d}$, $J=4.8 \mathrm{~Hz}, 1 \mathrm{H}), 2.44(\mathrm{~s}, 3 \mathrm{H}), 1.58(\mathrm{~s}, 3 \mathrm{H}), 1.25(\mathrm{~s}, 2 \mathrm{H})$ ppm; ${ }^{13} \mathrm{C}$ NMR $\left(100 \mathrm{MHz}, \mathrm{CDCl}_{3}\right): \delta 148.9,148.2,124.7$, 122.1, 21.2 ppm.

\section{Synthesis of $\left[\mathrm{Pb} 2(\mathrm{PHEN})_{2}(5-\mathrm{BTPC})_{2}(\mathrm{ACE})_{2}\right]$ (5)}

The procedure of preparation of (5) is similar to (3). Instead of 5-CTPC, 5-BTPC was used (Scheme 2) (yield

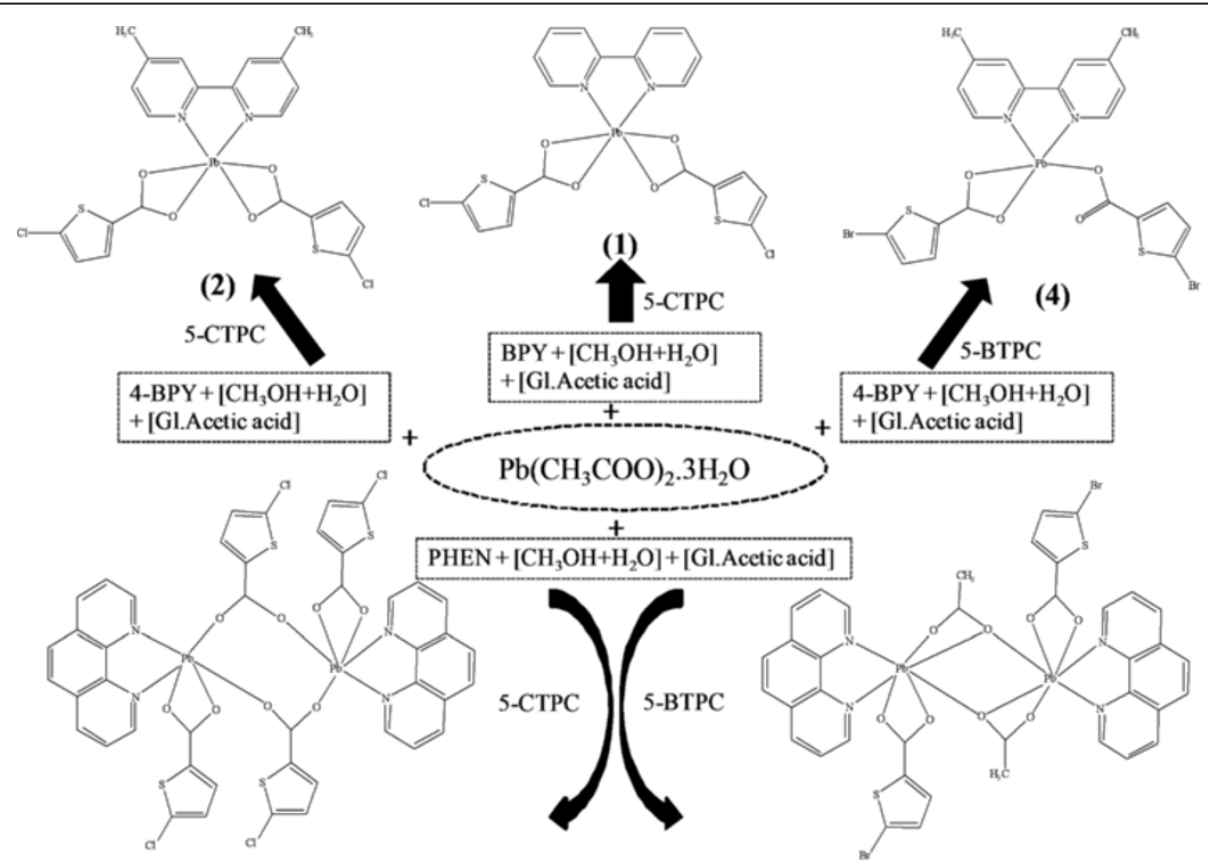

(3)
(5) 
Table 6 Selected bond lengths $(\AA)$ and bond angles $\left(^{\circ}\right)$ for complexes 1-5

\begin{tabular}{|c|c|c|c|c|c|c|c|c|c|c|c|}
\hline $\begin{array}{l}\text { Selected } \\
\text { bonds }\end{array}$ & $\begin{array}{l}\text { Value } \\
\text { (A) }\end{array}$ & $\begin{array}{l}\text { Selected } \\
\text { angles }\end{array}$ & $\left({ }^{\circ}\right)$ & $\begin{array}{l}\text { Selected } \\
\text { bonds }\end{array}$ & $\begin{array}{l}\text { Value } \\
\text { (Å) }\end{array}$ & $\begin{array}{l}\text { Selected } \\
\text { angles }\end{array}$ & $\left({ }^{\circ}\right)$ & $\begin{array}{l}\text { Selected } \\
\text { bonds }\end{array}$ & $\begin{array}{l}\text { Value } \\
\text { (Å) }\end{array}$ & $\begin{array}{l}\text { Selected } \\
\text { angles }\end{array}$ & $\left({ }^{\circ}\right)$ \\
\hline Complex 1 & & & & Complex 2 & & & & Complex 4 & & & \\
\hline Pb01-O1 & $2.532(2)$ & $\mathrm{O} 1-\mathrm{Pb} 01-\mathrm{O} 2$ & $51.55(6)$ & $\mathrm{Pb} 1-\mathrm{O} 1$ & $2.406(2)$ & $\mathrm{O} 1-\mathrm{Pb} 1-\mathrm{O} 2$ & $46.69(7)$ & $\mathrm{Pb} 1-\mathrm{O} 1$ & $2.407(3)$ & O1-Pb1-O4 & $\begin{array}{l}120.61 \\
(9)\end{array}$ \\
\hline $\mathrm{Pb} 01-\mathrm{O} 2$ & $2.586(2)$ & O1-Pb01-O3 & $85.29(6)$ & $\mathrm{Pb} 1-\mathrm{O} 2$ & $3.019(2)$ & O1-Pb1-O3 & $\begin{array}{l}120.44 \\
(7)\end{array}$ & $\mathrm{Pb} 1-\mathrm{O} 3$ & $2.349(2)$ & O1-Pb1-N1 & $\begin{array}{l}135.72 \\
(9)\end{array}$ \\
\hline Pb01-O3 & $2.518(2)$ & O1-Pb01-O4 & $\begin{array}{l}134.86 \\
(6)\end{array}$ & $\mathrm{Pb} 1-\mathrm{O} 3$ & $2.719(2)$ & O1-Pb1-O4 & $82.29(7)$ & $\mathrm{Pb} 1-\mathrm{O} 4$ & $2.718(4)$ & O1-Pb1-N2 & $\begin{array}{l}75.88 \\
(7)\end{array}$ \\
\hline $\mathrm{Pb01-O4}$ & $2.624(2)$ & O1-Pb01-N1 & $77.61(7)$ & $\mathrm{Pb} 1-\mathrm{O} 4$ & $\begin{array}{l}2.3469 \\
(19)\end{array}$ & O1-Pb1-N1 & $\begin{array}{l}134.83 \\
(7)\end{array}$ & $\mathrm{Pb} 1-\mathrm{N} 1$ & $2.631(3)$ & O3-Pb1-O4 & $\begin{array}{l}51.45 \\
(9)\end{array}$ \\
\hline Pb01-N1 & $2.481(2)$ & O1-Pb01-N2 & $\begin{array}{l}121.56 \\
(8)\end{array}$ & $\mathrm{Pb} 1-\mathrm{N} 1$ & $2.626(2)$ & O1-Pb1-N2 & $75.57(7)$ & $\mathrm{Pb} 1-\mathrm{N} 2$ & $2.585(3)$ & O3-Pb1-N1 & $\begin{array}{l}80.89 \\
(10)\end{array}$ \\
\hline \multirow[t]{10}{*}{ Pb01-N2 } & $2.595(2)$ & $\mathrm{O} 2-\mathrm{Pb} 01-\mathrm{O} 3$ & $\begin{array}{l}132.41 \\
(7)\end{array}$ & $\mathrm{Pb} 1-\mathrm{N} 2$ & $2.593(2)$ & O2-Pb1-O3 & $88.10(6)$ & & & $\mathrm{O} 3-\mathrm{Pb} 1-\mathrm{N} 2$ & $\begin{array}{l}86.18 \\
(8)\end{array}$ \\
\hline & & $\mathrm{O} 2-\mathrm{Pb} 01-\mathrm{O} 4$ & $\begin{array}{l}152.80 \\
(7)\end{array}$ & & & O2-Pb1-O4 & $83.59(6)$ & & & O4-Pb1-N1 & $\begin{array}{l}77.42 \\
(10)\end{array}$ \\
\hline & & O2-Pb01-N1 & $75.07(7)$ & & & O2-Pb1-N1 & $\begin{array}{l}162.85 \\
(6)\end{array}$ & & & O4-Pb1-N2 & $\begin{array}{l}126.01 \\
(8)\end{array}$ \\
\hline & & $\mathrm{O} 2-\mathrm{Pb} 01-\mathrm{N} 2$ & $75.97(7)$ & & & O2-Pb1-N2 & $\begin{array}{l}122.19 \\
(6)\end{array}$ & & & $\mathrm{O} 1-\mathrm{C} 1-\mathrm{O} 2$ & $\begin{array}{l}125.1 \\
(3)\end{array}$ \\
\hline & & O3-Pb01-O4 & $51.14(6)$ & & & O3-Pb1-O4 & $51.33(7)$ & & & & \\
\hline & & O3-Pb01-N1 & $77.00(7)$ & & & O3-Pb1-N1 & $77.62(7)$ & & & & \\
\hline & & O3-Pb01-N2 & $\begin{array}{l}123.39 \\
(8)\end{array}$ & & & O3-Pb1-N2 & $\begin{array}{l}126.66 \\
(6)\end{array}$ & & & & \\
\hline & & O4-Pb01-N1 & $81.02(7)$ & & & O4-Pb1-N1 & $80.09(7)$ & & & & \\
\hline & & $\mathrm{O} 4-\mathrm{Pb} 01-\mathrm{N} 2$ & $82.14(7)$ & & & O4-Pb1-N2 & $86.66(7)$ & & & & \\
\hline & & $\mathrm{N} 1-\mathrm{Pb} 01-\mathrm{N} 2$ & 64.29(8) & & & $\mathrm{N} 1-\mathrm{Pb} 1-\mathrm{N} 2$ & $62.21(7)$ & & & & \\
\hline Complex 3 & & & & Complex5 & & & & & & & \\
\hline $\mathrm{Pb} 1-\mathrm{O} 1$ & 2.453(3) & O1-Pb1-O3 & $\begin{array}{l}82.02 \\
(10)\end{array}$ & $\mathrm{Pb} 1-\mathrm{O} 1$ & $2.749(5)$ & O1-Pb1-O2 & $\begin{array}{l}50.02 \\
(12)\end{array}$ & & & & \\
\hline $\mathrm{Pb} 1-\mathrm{O} 2 \mathrm{i}$ & $2.741(3)$ & O1-Pb1-O4 & $\begin{array}{l}78.81 \\
(10)\end{array}$ & $\mathrm{Pb} 1-\mathrm{O} 2$ & $2.335(3)$ & O1-Pb1-O3 & $\begin{array}{l}119.74 \\
(11)\end{array}$ & & & & \\
\hline $\mathrm{Pb} 1-\mathrm{O} 3$ & $2.333(2)$ & O1-Pb1-N1 & $\begin{array}{l}135.32 \\
(11)\end{array}$ & $\mathrm{Pb} 1-\mathrm{O} 3$ & $2.633(5)$ & O1-Pb1-O4 & $\begin{array}{l}82.56 \\
(12)\end{array}$ & & & & \\
\hline $\mathrm{Pb} 1-\mathrm{O} 4$ & $2.816(3)$ & O1-Pb1-N2 & $\begin{array}{l}77.26 \\
(11)\end{array}$ & $\mathrm{Pb} 1-\mathrm{O} 4$ & $2.824(3)$ & O1-Pb1-N1 & $\begin{array}{l}79.17 \\
(12)\end{array}$ & & & & \\
\hline $\mathrm{Pb} 1-\mathrm{N} 1$ & $2.604(3)$ & $\mathrm{O} 1-\mathrm{Pb} 1-\mathrm{O} 2^{\mathrm{i}}$ & $\begin{array}{l}146.86 \\
(10)\end{array}$ & $\mathrm{Pb} 1-\mathrm{N} 1$ & $2.608(4)$ & O1-Pb1-N2 & $\begin{array}{l}120.32 \\
(11)\end{array}$ & & & & \\
\hline $\mathrm{Pb} 1-\mathrm{N} 2$ & $2.612(3)$ & O3-Pb1-O4 & 49.97(9) & $\mathrm{Pb} 1-\mathrm{N} 2$ & $2.577(4)$ & O1-Pb1-O1 & $\begin{array}{l}63.24 \\
(11)\end{array}$ & & & & \\
\hline \multirow[t]{6}{*}{$\mathrm{Pb} 1-\mathrm{Pb} 1^{\mathrm{i}}$} & $\begin{array}{l}3.7020 \\
(2)\end{array}$ & O3-Pb1-N1 & $75.55(9)$ & $\mathrm{Pb} 1-\mathrm{O} 1^{\mathrm{i}}$ & $2.909(5)$ & O2-Pb1-O3 & $\begin{array}{l}87.25 \\
(12)\end{array}$ & & & & \\
\hline & & O3-Pb1-N2 & $\begin{array}{l}86.32 \\
(10)\end{array}$ & & & $\mathrm{O} 2-\mathrm{Pb} 1-\mathrm{O} 4$ & $\begin{array}{l}83.42 \\
(10)\end{array}$ & & & & \\
\hline & & O2i-Pb1-O3 & $\begin{array}{l}102.13 \\
(10)\end{array}$ & & & $\mathrm{O} 2-\mathrm{Pb} 1-\mathrm{N} 1$ & $\begin{array}{l}79.52 \\
(10)\end{array}$ & & & & \\
\hline & & O4-Pb1-N1 & $\begin{array}{l}112.38 \\
(10)\end{array}$ & & & $\mathrm{O} 2-\mathrm{Pb} 1-\mathrm{N} 2$ & $\begin{array}{l}77.27 \\
(12)\end{array}$ & & & & \\
\hline & & $\mathrm{O} 4-\mathrm{Pb} 1-\mathrm{N} 2$ & $\begin{array}{l}132.48 \\
(10)\end{array}$ & & & $\mathrm{O} 1 \mathrm{a}-\mathrm{Pb} 1-\mathrm{O} 2$ & $\begin{array}{l}112.45 \\
(13)\end{array}$ & & & & \\
\hline & & O2i-Pb1-O4 & $\begin{array}{l}79.23 \\
(10)\end{array}$ & & & O3-Pb1 -O4 & $\begin{array}{l}47.69 \\
(13)\end{array}$ & & & & \\
\hline
\end{tabular}


Table 6 Selected bond lengths $(\AA)$ and bond angles $\left({ }^{\circ}\right)$ for complexes 1-5 (Continued)

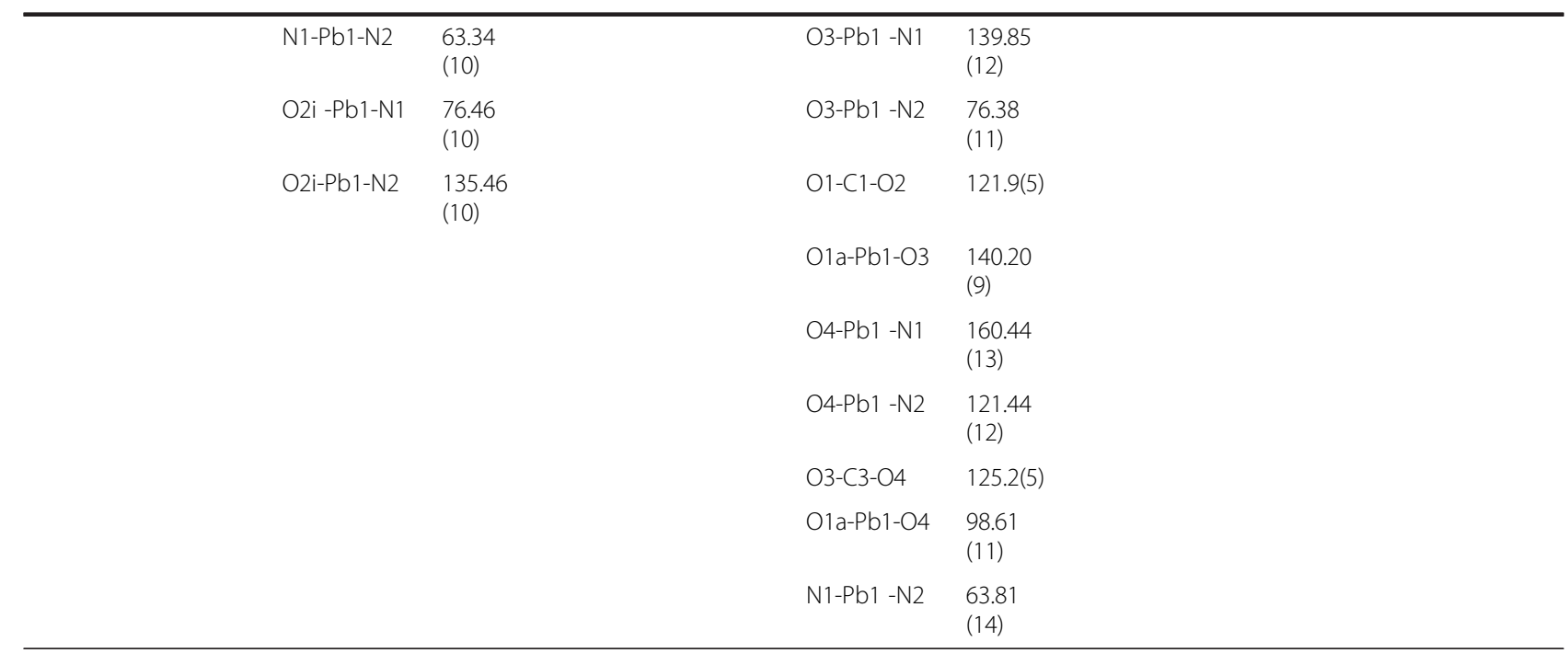

Complex 3 symmetry code (i):-x,1-y,1-z Complex 5 symmetry code (i): 2-x,1-y,1-z.

$67 \%$ based on $\mathrm{Pb})$. IR selected bands $\left(\mathrm{cm}^{-1}\right): 3388(\mathrm{w})$, 1562(s), 1358(s), 1098(s), 967(s), 843(s), 727(s), 766(s), $669512(\mathrm{~m}) .{ }^{1} \mathrm{H}$ NMR (400 $\left.\mathrm{MHz}, \mathrm{CDCl}_{3}\right): \delta 9.24-9.23$ $(\mathrm{m}, 2 \mathrm{H}), 8.28(\mathrm{~d}, J=9.6 \mathrm{~Hz}, 3 \mathrm{H}), 7.81-7.66(\mathrm{~m}, 4 \mathrm{H})$, $1.73(\mathrm{~s}, 3 \mathrm{H}), 1.25(\mathrm{~s}, 1 \mathrm{H}) \mathrm{ppm} ;{ }^{13} \mathrm{C} \mathrm{NMR}(100 \mathrm{MHz}$, $\left.\mathrm{CDCl}_{3}\right): \delta 150.3,146.2,136.1,128.7,126.6,123.2 \mathrm{ppm}$.

\section{Single crystal X-ray structure analysis}

Intensity data sets were collected at room temperature, on a BRUKER SMART APEXII CCD [56] area-detector diffractometer equipped with graphite monochromated Mo Ka radiation $(\lambda=0.71073 \AA)$. The data were reduced by using the program SAINT [56] and empirical absorption corrections were done by using the SADABS [56]. The structures were solved by direct methods using SHELXS-97 [57] and subsequent Fourier analyses, refined anisotropically by full-matrix least-squares method using SHELXL-97 [57] within the WINGX suite of software, based on F2 with all reflections. All carbon hydrogens were positioned geometrically and refined by a riding model with $\mathrm{U}_{\text {iso }} 1.2$ times that of attached atoms. All non $\mathrm{H}$ atoms were refined anisotropically. The molecular structures were drawn using the ORTEP-III [58], POV-ray [59] and MERCURY [60]. Crystal data and the selected parameters for complexes 1-5 were summarized in (Tables 3 and 6) respectively. Selected hydrogen bonding geometries are listed in (Table 2). The crystals remained stable throughout the data collection.

\section{Conclusions}

A series of novel $\mathrm{Pb}(\mathrm{II})$ complexes in concert with 5-CTPC, 5-BTPC and corresponding bidentate chelating N.N' ligands have been synthesized and characterized.
There is significant structural diversity even though, in all the complexes the molar ratio of $\mathrm{Pb}$, carboxylate, $\mathrm{N}$, $\mathrm{N}$-chelating ligand (ie, 1:2:1) is the same. The complexes $1,2,4$ are mononuclear and are structurally diverse compared with 3, 5 which are dinuclear in nature. The observation of structures 2, 4 and 3, 5 show the structural changes made just chloro/bromo substituent of the thiophene ring. In addition to noncovalent interaction like $\mathrm{C}-\mathrm{H}$...O, which is the reason for assembly of primary motifs; various other interactions like X..., $\mathrm{H}$...X, $(\mathrm{X}=\mathrm{Cl} / \mathrm{Br})$ add additional support in organizing these supermolecules in to extended architectures. It is noteworthy that the organic ligands not only serve as a space filling component but they are also involved in structural propagation either by $\pi-\pi$ stacking or $\mathrm{C}-\mathrm{H} . . . \pi$ stacking interactions. Complexes 1-5 exhibit strong emissions and may be potential materials for emitting diode devices. However this work not only shows the influence of replacement of different ligands on the structure but also it illustrates the effects of substituent's on the ligands on the crystal structure and geometry of the central metal ion, which also provides valuable instruction in design of coordination complexes with desired supramolecular architectures.

\section{Additional file}

Additional file 1: contains the IR, NMR spectra and the TGA curves for complexes (1-5).

Competing interests

Both authors declare that they have no competing interests. 


\section{Authors' contributions}

This work was prepared in the research group of PTM. He proposed the work and drafted the manuscript. SJJ participated in the design and presiding the experiments, collected the X-ray data and drafted the manuscript. Both authors read and approved the final manuscript

\section{Acknowledgements}

SJJ thank the UGC-SAP for the award of RFSMS. The authors thank the DST India (FIST programme) for the use of the diffractometer at the School of Chemistry, Bharathidasan University, Tiruchirappalli, Tamilnadu, India.

The authors dedicate this paper to Professor P. Venuvanalingam and

Professor S. Kumaresan on the occassion of their 60th birthday.

Received: 11 June 2013 Accepted: 8 August 2013

Published: 15 August 2013

\section{References}

1. Cook TR, Zheng YR, Stang PJ: Metal-organic frameworks and self-assembled supramolecular coordination complexes: comparing and contrasting the design, synthesis, and functionality of metal-organic materials. Chem Rev 2012, 113:734-777.

2. Andrews MB, Cahill CL: Uranyl bearing hybrid materials: synthesis, speciation, and solid-state structures. Chem Rev 2012, 113:1121-1136.

3. Sun SH, Sun ZG, Zhu YY, Dong DP, Jiao CQ, Zhu J, Li J, Chu W, Tian H, Zheng MJ, Shao WY, Lu YF: Four novel oxomolybdenum-organodiphosphonate hybrids in the presence of $\mathrm{Cu}(\mathrm{II})$-organonitrogen building blocks: synthesis, crystal structures, and surface photovoltage properties. Cryst Growth Des 2012 13:226-238.

4. Yoshizawa M, Nakagawa J, Kumazawa K, Nagao M, Kawano M, Ozeki T, Fujita M: Discrete stacking of large aromatic molecules within organic-pillared coordination cages. Angew Chem Int Ed 2005, 44:1810-1813.

5. Tabatabaee $\mathrm{M}$ : Supramolecular assembled of hexameric water clusters into a 1D chain containing $\left(\mathrm{H}_{2} \mathrm{O}\right)_{6}$ and $\left[\left(\mathrm{H}_{2} \mathrm{O}\right)_{4} \mathrm{O}_{2}\right]$ stabilized by hydrogen bonding in a copper complex. Chem Central J 2012, 6:5

6. Sun WW, Cheng AL, Jia QX, Gao EQ: Metal-coordination-directed assembly of binuclear trigonal prisms and three-dimensional hydrogen-bonded networks. Inorg Chem 2007, 46:5471-5473.

7. $\mathrm{Xu}$ J, Raymond KN: Structurally characterized quadruple-stranded bisbidentate helicates. Angew Chem Int Ed 2006, 45:6480-6485

8. Senegas JM, Koeller S, Bernardinelli G, Piguet C: Isolation and characterization of the first circular single-stranded polymetallic lanthanide-containing helicate. Chem Commun 2005, 17:2235-2237.

9. Caulder DL, Raymond KN: Supermolecules by design. Acc Chem Res 1999 , 32:975-982

10. Muller IM, Möller D: Rational design of a coordination cage with a trigonal-bipyramidal shape constructed from 33 building units. Angew Chem Int Ed 2005, 44:2969-2973.

11. Peedikakkal AMP, Vittal JJ: Structural transformations of Pb (II)-trans-1, 2-bis (4'-pyridyl) ethene coordination polymers in solution. Cryst Growth Des 2011, 11:4697-4703.

12. Persson I, Lyczko K, Lundberg D, Eriksson L, Płaczek A: Coordination chemistry study of hydrated and solvated lead (II) ions in solution and solid state. Inorg Chem 2011, 50:1058-1072.

13. Chen PR, Wasinger EC, Zhao J, van der Lelie D, Chen LX, He C Spectroscopic insights into lead (II) coordination by the selective lead (II)-binding protein PbrR691. J Am Chem Soc 2007, 129:12350-12351.

14. Aslani A, Morsali A, Yilmaz VT, Kazak C: Hydrothermal and sonochemical synthesis of a nano-sized 2D lead(II) coordination polymer: a precursor for nano-structured PbO and PbBr2. J Mol Struct 2009, 929:187-192.

15. Sadeghzadeh $\mathrm{H}$, Morsali A: Hedge balls nano-structure of a mixed-ligand lead (II) coordination polymer; thermal, structural and X-ray powder diffraction studies. Cryst Eng Comm 2010, 12:370-372.

16. Chen XM, Liu GF: Double-stranded helices and molecular zippers assembled from single-stranded coordination polymers directed by supramolecular interactions. Chem Eur J 2002, 8:4811-4817.

17. Pyykko P: Relativistic effects in structural chemistry. Chem Rev 1988, 88:563-594

18. Rogan JR, Poleti DD, Karanović LČ: Crystal structure of a new zigzag chain $\mathrm{Cu}$ (II) complex with terephthalato and 1, 10-phenonthroline ligands, [Cu (C8H4O4)(C12H8N2)(H2O)] n. J Serb Chem Soc 2004, 69:353-362.
19. Ye CH, Sun HL, Wang XY, Huang RL, Li JR, Gao S: Synthesis and crystal structure of a phthalate-bridged copper (II) complex [Cu(L)(Phen)(H2O)] $\mathrm{H} 2 \mathrm{O}$ n. J Chem Crystallogr 2005, 35:381-384

20. Sun D, Cao R, Liang Y, Shi Q, Su W, Hong M: Hydrothermal syntheses, structures and properties of terephthalate-bridged polymeric complexes with zig-zag chain and channel structures. J Chem Soc Dalton Trans 2001, $16: 2335-2340$

21. Li L, Liao D, Jiang Z, Yan S: Synthesis, structure and magnetic properties of a one-dimensional chain complex $\{[\mathrm{Cu}(\mathrm{dmbpy})(\mathrm{N} 3)] 2(\mathrm{ta})\} 2 \mathrm{CH} 3 \mathrm{OH}$. 2H2O. J Mol Struct 2001, 597:157-162.

22. Yin YB, Yu HX: catena-Poly[[(4,7-diphenyl-1,10-phenanthroline)lead(II)]-[mu]benzene-1,4-dicarboxylato]. Acta Cryst E 2007, 63:m2803.

23. Xiao HP, Yuan JX: Bis(hydrogen 5-nitroisophthalato)(1,10-phenanthroline) lead(II) monohydrate. Acta Cryst E 2004, 60:m1501-m1503.

24. Sobanska S, Wignacourt JP, Conflant P, Drache M, Lagrene M, Holt EM: Synthesis, thermal analysis and crystal structure of lead (II) diaqua 3, 6-dicarboxylatopyridazine. Evaluation of performance as a synthetic precursor. New J Chem 1999, 23:393-396.

25. Beveridge A, Bushnell W: Pentagonal pyramidal lead coordination in the crystal structure of dimeric diaquopyridine-2, 6-dicarboxylatolead (II) pyridine-2, 6-dicarboxylic acid monohydrate. Can J Chem 1979, 57:2498-2503.

26. Harrowfield JM, Shahverdizadeh GH, Soudi AA: Supramolecular influences on metal ion coordination: Lead (II) under eight-coordination. Supramol Chem 2003, 15:367-373

27. Wei Y, Hou H, Li L, Fan Y, Zhu Y: From dicarboxylic acid to tetranuclear metallamacrocyclic complex and 1D and 2D polymers. Cryst Growth Des 2005, 5:1405-1413.

28. Preut H, Huber F, Hoffmann E: Structure of diphenyl lead 2, 6-pyridinedicarboxylate hydrate. Acta Cryst C 1988, 44:755-756

29. Dale SH, Elsegood MR, Kainth S: Poly [lead (II)-2-aqua-4-terephthalato]. Acta Cryst C 2004, 60:m76-m78.

30. Ying SM, Mao JG: Two new layered lead(II) diphosphonates with 1,3, 5-benzenetricarboxylate ligands as an intercalated species or a multidentate metal linker. J Mol Struct 2005, 748:63-70.

31. Ying SM, Mao JG: Novel layered lead (II) aminodiphosphonates with carboxylate-sulfonate and 1, 3, 5-benzenetricarboxylate ligands as pendant groups or intercalated species. Eur J Inorg Chem 2004, 6:1270-1276.

32. Song JL, Mao JG, Sun YQ, Clearfield A: Novel hybrid porous 3D networks of lead (II) diphosphonate and triphosphonate containing 1, 3, 5-benzenetricarboxylate. Eur J Inorg Chem 2003, 2003:4218-4226.

33. Kourgiantakis M, Matzapetakis M, Raptopoulou CP, Terzis A, Salifoglou A: Lead-citrate chemistry. Synthesis, spectroscopic and structural studies of a novel lead (II)-citrate aqueous complex. Inorg Chim Acta 2000, 297:134-138.

34. Xu KX: Handbook of Fine Organic Chemical Engineering Raw Material and Intermediate. Beijing: Chemical Industry; 1986

35. Gong $Y$, Wang $T$, Zhang $M, H u$ CW: Synthesis, structure and property of metal thiophene 2, 5-dicarboxylates: Novel three dimensional coordination polymers. J Mol Struct 2007, 833:1-7.

36. Chen BL, Mok KF, Ng SC, Drew MG: Syntheses, structures and properties of copper(II) complexes with thiophene-2,5-dicarboxylic acid $\left(\mathrm{H}_{2} \mathrm{Tda}\right)$ and nitrogen-containing ligands. Polyhedron 1999, 18:1211-1220.

37. Chen BL, Mok KF, Ng SC, Feng YL, Liu SX: Synthesis, characterization and crystal structures of three diverse copper (II) complexes with thiophene-2, 5-dicarboxylic acid and 1, 10-phenanthroline. Polyhedron 1998, 17:4237-4247.

38. Sun XZ, Sun YF, Ye BH, Chen XM: Hydrogen-bonding organization of $(4,4)$ coordination layers into a 3-D molecular architecture with channels clathrating guest molecules $\left[\mathrm{Cu}(\mathrm{tdc})(\mathrm{bpy})\left(\mathrm{H}_{2} \mathrm{O}\right)\right]$ (bpy) (tdc $=$ thiophine-2,5dicarboxylate; bpy =4,4'-bipyridine). Inorg Chem Commun 2003, 6:1412-1414.

39. Sun XZ, Huang ZL, Wang HZ, Ye BH, Chen XM: Syntheses and crystal structures of cadmium complexes with thiophenedicarboxylate and bipyridine-like ligands. Z Anorg Allg Chem 2005, 631:919-923.

40. Yu JH, Ding CJ, Han KF, Zhang SW, Guo HY: Synthesis, crystal structure and optical properties of a novel organic-inorganic hybrid material $[\mathrm{Ag}(\mathrm{bpp})]_{2}(\mathrm{tdc}) \cdot 8 \mathrm{H} 2 \mathrm{O}$. Chin J Inorg Chem 2006, 22:607-611.

41. Chen BL, Mok KF, Ng SC, Drew MGB: Thiophene-2, 5-dicarboxylic acid incorporated self- assembly of one-, two- and three-dimensional coordination polymers. New J Chem 1999, 23:877-883.

42. Jenniefer SJ, Muthiah PT: Supramolecular architectures of two novel organic-inorganic hybrid materials containing identical monomeric uranyl units. Acta Cryst C 2011, 67:m69-m72. 
43. Jenniefer SJ, Muthiah PT, Priyadharshni R: Syntheses, characterization, and supramolecular architectures of two lead(II) complexes of 8-quinolinol. J Coord Chem 2012, 65:4397-4408.

44. Jenniefer SJ, Muthiah PT: Synthesis, characterization and X-ray structural studies of four copper (II) complexes containing dinuclear paddle wheel structures. Chem Central J 2013, 7:35.

45. Jennifer SJ, Muthiah PT, Muthukumaran G: Solvent persuading supramolecular interactions in two 5-Chloro thiophene 2-carboxylate bridged dinuclear copper (II) complexes. Inorg Chim Acta 2013, 406:100-105.

46. Zheng XF, Zhou YX, Wan XS, Zhang HY, Niu YY, Yang R, Niu CY, Wu BL: Syntheses, crystal structures and properties of two novel supramolecular complexes with $a$-thiophene carboxylate, $\left[\mathrm{Pb}\left(\right.\right.$ phen) $\left.(\mathrm{tpa})_{2}\right]$ and [Cu(im) $)_{2}$ tpa)2H2O $($ phen = 1, 10-phenanthroline, tpa = thiophene carboxylic acid, im = imidazole). Synth React Inorg Metal Org Nano Metal Chem 2007, 37:255-261.

47. Shimoni-Livny L, Glusker JP, Bock CW: Lone pair functionality in divalent lead compounds. Inorg Chem 1998, 37:1853-1867.

48. Hancock RD, Williams AF, Floriani C, Merbach AE: Perspectives in Coordination Chemistry. Basel: VCHA, VCH; 1992:129.

49. Fan SR, Zhu LG: Influence of the reaction conditions on the self-assembly of lead (II) 5-sulfosalicylate coordination polymers with chelating amine ligands. Inorg chem 2006, 45(19):7935-7942.

50. Shahverdizadeh GH, Soudi AA, Morsali A, Retailleau P: Four mixed-ligands lead(II) complexes based on 8-hydroxyquinolin (8-HQuin), [Pb(8-Quin)X]; $\mathrm{X}=4$-pyridinecarboxylate, acetate, thiocyanate and nitrate; structural and thermal studies. Inorg Chim Acta 2008, 361:1875-1884.

51. Bernstein J, Davis RE, Shimoni L, Chang NL: Patterns in hydrogen bonding: functionality and graph set analysis in crystals. Angew Chem Int Ed Engl 1995, 34:1555-1573.

52. Virtual special issue: Halogen Bonding in Crystal Engineering: Fundamentals and Applications.; 2012. http://pubs.acs.org/page/cgdefu/vi/8.

53. Andrews MB, Cahill $\mathrm{CL}$ : Utilizing hydrogen bonds and halogen-halogen interactions in the design of uranyl hybrid materials. Dalton Trans 2012, 41:3911-3914.

54. Brammer L, Bruton EA, Sherwood P: Understanding the behavior of halogens as hydrogen bond acceptors. Cryst Growth Des 2001, 1:277-290.

55. Chen XL, Zhang B, Hu HM, Fu F, Wu XL, Qin T, Yang ML, Xue GL, Wang JW: Three novel heterobimetallic $\mathrm{Cd} / \mathrm{Zn}$ - Na coordination polymers: syntheses, crystal structure, and luminescence. Cryst Growth Des 2008, 8:3706-3712.

56. Bruker: APEX2, SAINT and SADABS. Madison,Wisconsin, USA: Bruker AXS Inc; 2008

57. Sheldrick GM: Acta Cryst A 2008, 64:112.

58. Spek AL: Acta Cryst D 2009, 65:148.

59. Farrugia LJ: POV-Ray - 3.5. Australia: Glasgow University; 2003.

60. Macrae CF, Bruno IJ, Chisholm JA, Edgington PR, McCabe P, Pidcock E, Rodriguez-Monge L, Taylor R, van de Streek J, Wood PA: Mercury CSD 2.0 - new features for the visualization and investigation of crystal structures. J Appl Crystallogr 2008, 41:466-470.

doi:10.1186/1752-153X-7-139

Cite this article as: Jennifer and Thomas Muthiah: Supramolecular architectures and structural diversity in a series of lead (II) Chelates involving 5-Chloro/Bromo thiophene-2-carboxylate and $\mathrm{N}, \mathrm{N}^{\prime}$-donor ligands. Chemistry Central Journal 2013 7:139.

Publish with ChemistryCentral and every
scientist can read your work free of charge
"Open access provides opportunities to our
colleagues in other parts of the globe, by allowing
anyone to view the content free of charge."
W. Jeffery Hurst, The Hershey Company.
- available free of charge to the entire scientific community
- peer reviewed and published immediately upon acceptance
- cited in PubMed and archived on PubMed Central
- yours - you keep the copyright
Submit your manuscript here:
http://www.chemistrycentral.com/manuscript/

